\title{
COMING UP TRUMPS: \\ A STUDENT MUSIC THERAPIST SUPPORTS \\ YOUNG PEOPLE WITH HIGH OR VERY HIGH \\ COMPLEX SPECIAL NEEDS TO DEVELOP THE \\ KEY COMPETENCIES
}

\author{
An exegesis submitted to \\ Massey University and Victoria University of Wellington \\ in partial fulfilment for the degree of \\ Master of Music Therapy
}

New Zealand School of Music

Sarah Hall 


\begin{abstract}
This exploratory study aimed to discover and highlight the techniques and strategies that supported young people with high or very high complex special needs to develop the key competencies during music therapy sessions at a special school. Music therapy was carried out on an individual basis in a naturalistic manner and clinical notes were produced to record details that seemed important in each session. This data was then reviewed retrospectively in a process known as secondary analysis, employing both deductive and inductive modalities to search for and draw out links to the key competencies. A process of coding data within each key competency category revealed emerging themes and found that a number of musical, verbal and/or physical techniques and strategies supported the five key competencies during therapy. The categories, themes and codes have been defined and described with examples from the data, and a clinical vignette is included for further explanation. The data demonstrated the holistic nature of music therapy in that many techniques and strategies worked to support all five key competencies, even when the focus was a single competency. The findings are discussed with reference to, and in light of, current literature and suggested that the techniques and strategies used within my music therapy practice strongly relate to the key competencies and provide a unique context for their development. It is noted that the findings cannot be generalised to other settings and populations. However, this in-depth study may provide insight into the potential educational benefits and links between music therapy practice and the key competencies for those working with young people who have high or very high complex special needs.
\end{abstract}




\section{ACKNOWLEDGEMENTS}

The journey of becoming a music therapist and completing this research project has been, at times, challenging and yet one of the most rewarding journeys I have ever been on. However, I would not have been able to do it alone and would therefore like to thank:

My supervisor, Dr Daphne Rickson, for your invaluable insight, wisdom, support and continuous encouragement throughout this process. Your passion for music therapy practice and research made this journey feel exciting and achievable, and I am so grateful for the kindness, honesty and care you have shown me. Thank you.

Dr Sarah Hoskyns, for all of the knowledge and advice you have given me over the past two years.

My classmates! It has been incredible to share this journey with you all. I will forever cherish your support, friendships and our many hours of making music together.

All of the staff members at my placement, for your constant support, encouragement and friendships. You always made me feel like part of the team.

My incredible family and friends - thank you for your never-ending love, support, encouragement, and belief in me. I would not be where I am today without you.

All of the students I had the pleasure of working with. What a privilege it was to get to know each and every one of you. You filled my days with fun and laughter, and taught me so much in the three terms I worked with you. Thank you for this incredible and unforgettable experience!

Ethical approval has been gained from the Massey University Human Ethics Committee for this research project (HEC: Southern Application - 11/41) 


\section{TABLE OF CONTENTS}

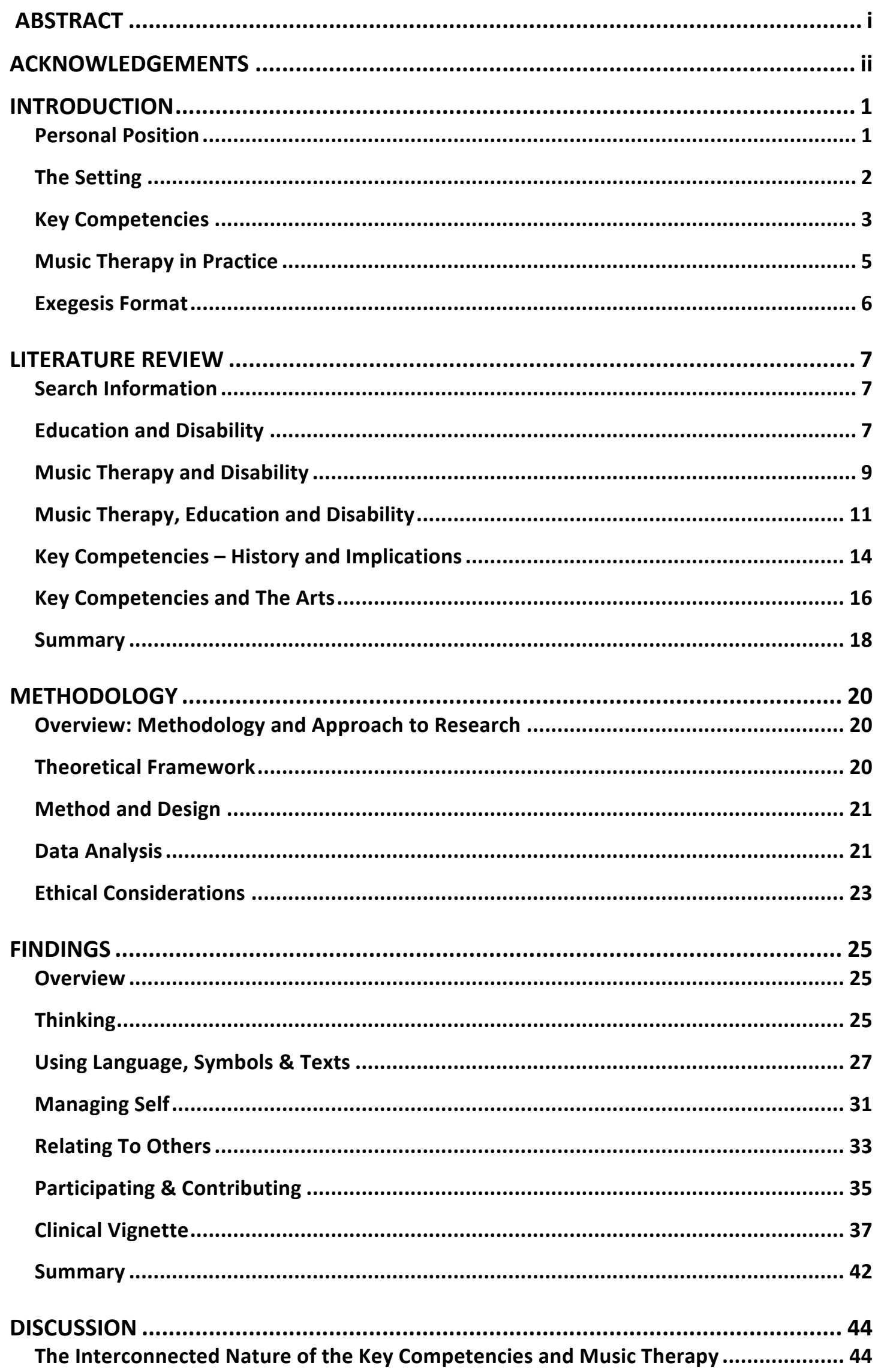


Common Techniques and Strategies Within My Music Therapy Practice ...................... 45

Supporting and Challenging for Success - Finding a Balance ....................................... 47

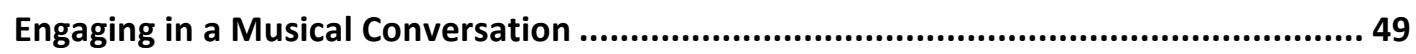

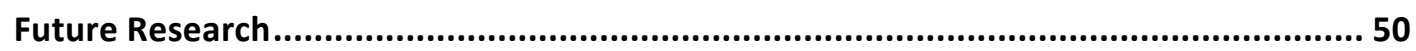

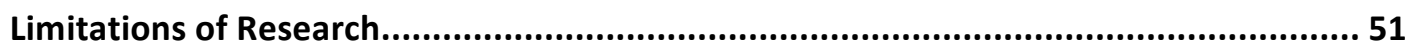

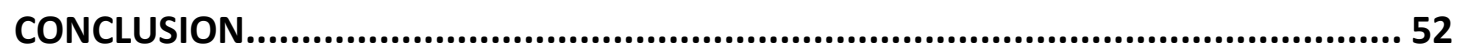

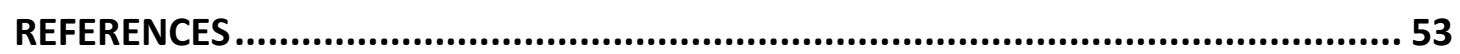

APPENDIX 1: Example of Initial Coding ...............................................................62 62

APPENDIX 2: Example of Sorting Initial Codes ....................................................63 63

APPENDIX 3: Example of Emerging Themes ........................................................ 64

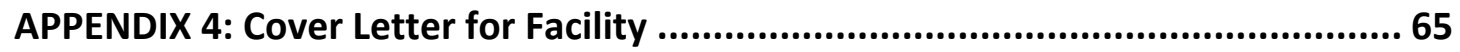

APPENDIX 5: Consent Form for Facility ...........................................................67

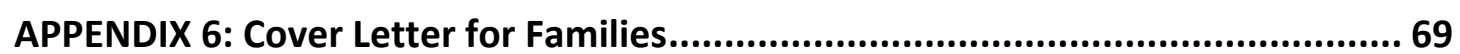

APPENDIX 7: Information Sheet for Families ..................................................... 70

APPENDIX 8: Consent Form for Families: ....................................................... 72

APPENDIX 9: Overview of the Key Competencies Pathway .................................. 73 


\section{INTRODUCTION}

This qualitative study is a by-product of my 750-hour clinical placement as a music therapy student at a special school. The research question emerged as I read about music therapy in special education settings and familiarised myself with the New Zealand Curriculum (Ministry of Education, 2007) before beginning my placement at the school. The key competencies outlined in the curriculum stood out as especially important as "people use [them] to live, learn, work, and act as active members of their communities" (Ministry of Education, 2007, p. 12). I became interested in how music therapy and the key competencies could work together to support student learning and ultimately enhance their lives both now and in the future. This interest led to the following research question and subsequent study:

How did I support students with high or very high complex special needs to develop the key competencies outlined in the New Zealand Curriculum?

The title 'Coming Up TRUMPs' (Thinking, Relating To Others, Using Language, Symbols \& Texts, Managing Self, and Participating \& Contributing - the five key competencies (Ministry of Education, 2007)) refers to the gains I saw students make towards developing the key competencies during my time working with them.

\section{Personal Position}

For as long as I can remember, music has played a large role in my life. Growing up in a musical family, my formal training began with the violin at the age of seven. My interest developed as I picked up other instruments, both formally and informally, as the years progressed. As much as I enjoyed the music itself, I began to enjoy the social aspects of music during my teenage years as I sang in a number of school 
choirs, at my local church, in a Barbershop Chorus, played in a few orchestras, and eventually taught violin and vocals to both children and adults.

Similarly, my first experience with someone with special needs was at the age of six - an experience that would influence the direction of my life. One of the students in my class, during my second year at primary school, was a girl who had a developmental delay and was mostly non-verbal. I found myself drawn to her, inviting her to play with me during lunch times and often spending time with her in the classroom. Unlike other students, I found it easy to interact with her and our friendship seemed mutual. During the next four years at primary school we continued to be in the same class and our friendship grew. I also began spending time with other students with similar needs in other classrooms, and in the onsite special needs unit attached to our school.

When I began my placement at the school I was reminded of my time spent with students in the special needs unit at primary school and quickly felt that same easiness and connection with the students I began working with. While I knew from my own experience that musical encounters could provide social interactions and a sense of enjoyment, I was eager to see how my music therapy work could support students' educational goals and align with the New Zealand Curriculum.

\section{The Setting}

The school is a purpose built special school, catering to students between 5-21 years of age with a diverse range of needs. Students enrolled at the school must have a significant physical disability and be confirmed as having either high or very high complex special needs ${ }^{1}$ under the Ongoing Resourcing Scheme $(\mathrm{ORS})^{2}$ (Ministry of

\footnotetext{
${ }^{1}$ I have chosen to use the term 'high or very high complex special needs' for this population group as it seems to best describe the high level and the complicated nature of the students needs, and is used by the school and the wider education sector within New Zealand.
} 
Education, 2014c). The school offers a holistic approach to education and learning, with a range of ongoing therapies, including music therapy, available to all students onsite. The teaching and therapeutic teams work together with each student and their whanau ${ }^{3}$ to set and implement learning and functional goals. These goals cover all areas of a student's life and may include physical, communicative, cognitive, social, personal and emotional areas of need. Goals are outlined in each student's Individual Education Plan (IEP) set by school staff along with students' families, to support students to effectively access the New Zealand Curriculum. The school's holistic approach gives students the opportunity to learn and develop successfully, and is concerned with more than just academic learning. Life skills are one of the non-academic focuses within the school, giving students the opportunity to learn skills that will directly impact their future and their ability to become more independent. This is linked to the school's emphasis on improving student wellbeing and wholeness in order for students to realise their full potential.

\section{Key Competencies}

The key competencies outlined in the New Zealand Curriculum (Ministry of Education, 2007) are explained as the competencies people need "to live, learn, work, and contribute as active members of their communities" (p. 12). As part of the curriculum, it is expected that students have opportunities to develop these competencies to become "lifelong learners" (Ministry of Education, 2007, p. 4). While the school ran somewhat differently from mainstream schools, it seemed as though the teachers' focus was on students' development of the key competencies along with IEP goals. The therapists, on the other hand, seemed to attend primarily to specific student goals pertaining to their field of expertise, while remaining aware of the students' development as a whole. Following this model, my focus within

\footnotetext{
2 "The Ongoing Resourcing Scheme (ORS) provides support for students with the highest level of need for special education to join in and learn alongside other students at school" (Ministry of Education, 2014c, p. 1).

${ }^{3}$ Whanau is a Maori word, commonly used throughout New Zealand, meaning 'family'.
} 
music therapy sessions was also on IEP goals that were typically developmentally based. While there were links between most students IEP goals and the key competencies, I was not focused on these links during music therapy sessions.

The key competencies are clearly outlined within the New Zealand Curriculum (Ministry of Education, 2007) and these definitions played a large role in informing my research. However, due to the high needs of the students and the level at which they were working, the definitions provided within the curriculum often seemed obscure. The Key Competencies Pathway document (KCP Curriculum Group, 2012) (see Appendix 9) was therefore used in conjunction with the curriculum in order to understand what the competencies looked like for students working at level one of the curriculum.

A definition of the five key competencies at level one of the curriculum follows:

- Thinking: "is about using creative, critical, and metacognitive processes to make sense of information, experiences and ideas. These processes can be applied to purposes such as developing understanding, making decisions, shaping actions, or constructing knowledge" (Ministry of Education, 2007, p. 12). Students working at level one of the NZC are encouraged to actively seek knowledge by exploring and showing an interest in the world around them (KCP Curriculum Group, 2012).

- Using Language, Symbols \& Texts: "is about working with and making meaning of the codes in which knowledge is expressed. Languages and symbols are systems for representing and communicating information, experiences, and ideas." (Ministry of Education, 2007, p. 12). Students must learn to work with language, symbols and texts to "convey meaning by using specific words, symbols, images, sounds, movements and/or technologies" (KCP Curriculum Group, 2012, To Work With Language, Symbols and Text section) in order to express themselves.

- Managing Self: “is associated with self-motivation, a 'can-do' attitude, and with students seeing themselves as capable learners. ... Students who manage themselves are enterprising, resourceful, reliable, and resilient" 
(Ministry of Education, 2007, p. 12). Students are required to act independently, meet challenges and use their initiative in a range of familiar and unfamiliar situations (KCP Curriculum Group, 2012).

- Relating To Others: "is about interacting effectively with a diverse range of people in a variety of contexts. This competency includes the ability to listen actively, recognise different points of view, negotiate and share ideas." (Ministry of Education, 2007, p. 12). In order to successfully interact with others, students must be able to express themselves, their feelings and ideas, and learn from and with the people around them (KCP Curriculum Group, 2012).

- Participating \& Contributing: "is about being actively involved in communities. ... This competency includes a capacity to contribute appropriately as a group member, to make connections with others, and to create opportunities for others in the group" (Ministry of Education, 2007, p. 13). Students are required to develop confidence in order to try new activities, respond to questions that influence the group and contribute ideas as a valued member of team (KCP Curriculum Group, 2012).

\section{Music Therapy in Practice}

When I began my placement, group and individual music therapy sessions were already part of the school's programme and, Amanda ${ }^{4}$, a music therapist, was employed as part of the school's therapy team. Initially, I began working with students individually, taking them out of their classroom to work with them in a private room. Over time I also began to facilitate a number of group sessions, either with a whole class or a mixed group of students with similar needs, although data from these sessions has not been included in this study.

At the beginning of my time at the school, Amanda and I discussed which of the

\footnotetext{
${ }^{4}$ Name has been changed in order to keep anonymity.
} 
students would benefit from individual music therapy sessions. Amanda was able to give me insight into each student's likes and dislikes, what they responded well to, and their specific needs. I also read each student's IEP in order to gain more knowledge of them, their goals and how the multidisciplinary team was working to support them. This information was extremely beneficial, as I was well informed about each student before beginning music therapy sessions with them, and was able to link my work to that of other team members.

Typically, I met each student in their own classroom and took them to a private room where we were able to work one-on-one without interruption. Session activities included improvisation, singing and playing familiar songs, moving to music, and composing songs. Sessions usually began with a 'hello song' and closed with a 'goodbye song' in order to clearly define the beginning and end. However, in working within a client-centred approach, sessions were developed to be student specific and the activities used in each session were chosen to meet particular student goals. Over time I was able to learn student preferences and chose activities that incorporated the things that students enjoyed most. Clinical notes containing session observations of my work with eight students over a ten-week period were analysed to uncover potential links to the key competencies.

\section{Exegesis Format}

Following this general introduction, I present a brief review of the literature relating to education, music therapy and disability in order to provide a context for the research. The methodology section describes the methods of data collection and analysis used in this study to answer the research question, as well as the methodology and theoretical framework that underpin the methods employed. The findings are then explained and discussed in relation to the literature before giving recommendations for future research. 


\section{LITERATURE REVIEW}

\section{Search Information}

The literature review that follows includes the material that was found while undertaking both online searches and physical searches in libraries. Online searches were completed through a number of databases, primarily Massey University library's EBSCOhost Discovery Science, SAGE Journals Online, Scopus, Google Scholar, and Web of Science. Search strings were mainly used during online searches, combining keywords and phrases in the search field to find specific, relevant literature. Examples of the search strings used include "profound disability", "school" and "music therapy"; "multiple disability", "special school" and "music therapy"; "very high needs", "education" and "music therapy"; "music therapy", "education" and "key competencies"; "profound disability", "education" and "key competencies"; and other combinations of these keywords and phrases. Additional online material was found through searches on the Ministry of Education websites. Physical searches were conducted primarily at the Massey University library in order to find relevant educational or therapeutic material. When collecting literature, a preference was placed on more recent works, specifically those produced within the least ten years.

\section{Education and Disability}

"The role of education is to nurture, grow and realise every child's potential" (Ministry of Education, 2014e, p. 1).

Education in New Zealand is underpinned by a number of documents and laws developed by the government and Ministry of Education in order to set the direction of education for all students. The current Education Act, established in 1989, is the overarching document that sets the standard for quality of education within New Zealand primary, secondary and tertiary institutions (Ministry of Education, 2014a). 
It outlines the educational requirements for all students, education providers and the New Zealand government, whether the students have special education needs or not (Ministry of Education, 2014a). Section 8 of the Act states, "people who have special educational needs (whether because of disability or otherwise) have the same rights to enrol and receive education in state schools as people who do not" (Ministry of Education, 2014a, p. 53). Thus all students are entitled to free, equitable education regardless of their individual circumstances (Minister for Disability Issues, 2001; Ministry of Education, 2014a, 2014d).

The New Zealand Curriculum (NZC), on the other hand, expresses the specifics of what is deemed important in education so that students may become "lifelong learners who are confident and creative, connected, and actively involved" (Ministry of Education, 2007, p. 4). It "applies to all English-medium state schools ... and to all students in those schools, irrespective of their gender, sexuality, ethnicity, belief, ability or disability, social or cultural background, or geographical location" (Ministry of Education, 2007, p. 6). The NZC aims to direct student learning and guide schools as they implement, teach and support the development of the values, key competencies and learning areas through their unique school curricula (Ministry of Education, 2007). It endeavours to remove all barriers for students' education by placing them at the centre of teaching and learning, and empowering them to achieve their personal best and realise their full potential (Ministry of Education, 2007, 2014b, 2014e).

Supporting students with disabilities and special education needs to access and engage with the NZC and school programmes is important for their learning, development and success in life (Ministry of Education, 2007, 2014d). Individual Education Plans (IEP) help schools to identify student's strengths and areas of need in order to adapt school programmes and support student curriculum learning (Ministry of Education, 2011). This promotes the idea that every student is a capable learner and enables education facilities to provide optimum learning opportunities for all students in an inclusive environment (Ministry of Education, 2007, 2014d, 2014e) in order to "achieve a world-class education system with learning 
opportunities of equal quality for all students" (Ministry of Education, 2011, p. 2).

Achievement for these students is largely dependent on the successful collaboration and participation of parents, families and schools within the IEP process, as well as positive, encouraging student-teacher relationships (Ministry of Education, 2011, 2014d). Including and supporting families and staff in the IEP process empowers them to be confident and actively involved in the decision-making and implementation of adapted programmes, extra assistance and specialised equipment (Ministry of Education, 2011, 2014d, 2014e). Thus, young people with disabilities and special education needs have the opportunity to access a quality inclusive education that addresses the whole person, taking into consideration every environment that they are a part of (Adamek \& Darrow, 2010; Ministry of Education, 2014d). In doing this, the aim of achieving "a world class inclusive education system that provides learning opportunities of equal quality to all children and school students" (Ministry of Education, 2014d, p. 1) becomes a greater reality.

\section{Music Therapy and Disability}

Music has the innate ability to subconsciously evoke emotional responses from humans. Foran states that its power "is used by advertising companies, film directors, and mothers singing their babies to sleep" (2009, p. 51). Its effects are universal and have been used for thousands of years. Music therapy, however, is a more recent development, initially used with returning war veterans as part of their rehabilitation when returning from battle in World War II (Foran, 2009; Rickson \& McFerran, 2007). Because of its innate power, music therapy has since grown allowing music therapists to work in a wide range of settings to support people to meet a variety of goals and needs.

Music therapy is philosophically holistic in nature, taking into consideration all areas of ones life in order to assist and encourage the wellbeing of the whole person (Kennedy \& Scott, 2005; Rickson \& McFerran, 2007). Trained music therapists can 
"facilitate and promote communication, relationships, learning, mobilisation, expression, organisation and other relevant therapeutic objectives, in order to meet physical, emotional, mental, social and cognitive needs" (World Federation of Music Therapy, 1996, cited in Rickson \& McFerran, 2007, p. 40) through the use of a range of musical activities. Specific needs are addressed within music therapy sessions. However, the overarching goal for all music therapy participants is to improve quality of life and see participants reach full potential through the medium of music (Gooding, 2011; McFerran \& Shanahan, 2011; McFerran \& Shoemark, 2013; Pienaar, 2012; Rickson \& McFerran, 2007).

Music therapy has been used to assist people with disabilities for over half a century, resulting in a large percentage of music therapists working with this population group. Nordoff and Robbins were pioneers in this area, developing a specific music therapy approach for working with children who have severe disabilities (Pienaar, 2012; Youngshin Kim, 2004). This approach sees every person as having an inborn musicality that can be awakened through improvisational musical encounters that encourage the development of communication and relationships and sees participants reach their full potential (Stephenson, 2006; Youngshin Kim, 2004). However, music therapists realise that each participant is unique and responds to music differently. Each session must, therefore, be tailored for a specific participant in order to be the most effective in meeting goals and improving wellbeing (Stephenson, 2006; Youngshin Kim, 2004). Thus, music therapists require flexibility to respond to participant needs 'in the moment', allowing for spontaneity in order to discover and unfold creative potential (Nordoff-Robbins Music Therapy, 2011; Youngshin Kim, 2004).

The literature suggests that music therapy is often an engaging and motivational experience for those with disabilities (Daveson \& Edwards, 1998; Pellitteri, 2000; Perry, 2003; Rickson \& McFerran, 2007). It is stated that music therapy is far reaching, crossing many areas of treatment and addressing multiple areas of need and development at once (Pellitteri, 2000). A range of verbal and non-verbal musical experiences can serve to engage, stimulate, maintain and focus attention; and allow 
for repetition without the experience becoming monotonous (Gooding, 2011; Pellitteri, 2000; Perry, 2003; Rickson \& McFerran, 2007). Activities can include singing, playing instruments, improvising, using familiar songs, music and movement, listening to music, song writing, composition and lyric substitution. These serve as a way of engaging participants, overcoming obstacles and effectively meeting their goals, consequently improving their quality of life and wellbeing (Daveson \& Edwards, 1998; Gooding, 2011; McFerran \& Shanahan, 2011; Patterson, 2003; Pellitteri, 2000; Pienaar, 2012; Rickson \& McFerran, 2007).

The development of a positive client-therapist relationship within music therapy sessions is an important part of this work, and it is suggested that this aspect is especially important for students with disabilities or high/very high special needs (McFerran \& Shoemark, 2013). Relationships are typically regarded as being of equal importance to musical experiences as they have a direct impact on the development and wellbeing of the participant (Kennedy \& Scott, 2005; McFerran \& Shanahan, 2011; McFerran \& Shoemark, 2013; Pellitteri, 2000; Perry, 2003; Pienaar, 2012; Rickson \& McFerran, 2007; Stephenson, 2006). The relationship is established and built over time, through and within the music, and is essential to the process that takes place within music therapy (McFerran \& Shanahan, 2011; McFerran \& Shoemark, 2013). Thus, a positive client-therapist relationship, alongside a range of musical experiences, offers those with disabilities a potentially more effective intervention for producing change and consequently a better quality of life than either one alone.

\section{Music Therapy, Education and Disability}

Since its establishment as a profession, music therapy has been used as an additional educational support for students with special needs and disabilities (McFerran \& Shanahan, 2011). In this capacity, music therapists typically operate within the allied health team, working holistically to improve student wellbeing and quality of life (Pienaar, 2012; Rickson \& McFerran, 2007). For those with special education needs, 
it is imperative that a holistic approach is utilised in order to meet the needs of the whole person. Daveson and Edwards (1998) state, "music therapy practice embodies the philosophical principles on which special education services are based as it aims to assist students' cognitive, psychological, physical and socio-emotional development" (Daveson \& Edwards, 1998, p. 2). This suggests that music therapy and special education are naturally able to work hand-in-hand to support the learning and development of those with special needs.

The literature is rich in research describing the use of music therapy with students who have a range of special education needs in mainstream schools, units and special education settings in order to meet non-musical educational goals. Music therapists employed as specialists, partner with the teaching team to assist students in achieving educational and IEP goals typically where music is a particularly motivating activity for a student (Daveson \& Edwards, 1998; McFerran \& Shanahan, 2011; Patterson, 2003; Pellitteri, 2000; Stephenson, 2006). “A critical element for including music therapy in IEPs is determining its effectiveness in attaining target IEP goals and thus establishing it as an education benefit" (Pellitteri, 2000, p. 387). A holistic framework underpins special education, which means 'educational benefits' are more than academic achievements and include social and emotional benefits (Turnbull \& Turnbull, 1998). Therefore, music therapists typically undertake a process of referral, assessment, treatment, documentation and evaluation, alongside developmental and behavioural approaches, in order to align the intervention with educational goals and justify its place in an IEP (McFerran \& Shanahan, 2011; Rickson \& McFerran, 2007).

Historically, when working with students with intellectual disabilities, music therapists employed in educational settings have worked primarily towards communicative, motoric and social goals (McFerran \& Shoemark, 2013). Current music therapy research supports a focus on communication development for students with a range of communication needs. For those with severe communication difficulties, music therapy can bridge the gap and be used as an alternative means of communication while fostering both musical and other 
developmental skills (McFerran \& Shanahan, 2011; Pellitteri, 2000; Perry, 2003; Pienaar, 2012; Stephenson, 2006). Music therapists can encourage imitation and echoing of sounds, rhythms and words, while providing rhythmic structure and language cues that are important in speech and language (Kennedy \& Scott, 2005; Pienaar, 2012). Singing has also been noted to improve and develop fluency, diction, intonation and rate of speech, in a natural manner, while being a motivating repetitive activity (Kennedy \& Scott, 2005; Pienaar, 2012). Where communication is difficult, "music therapy can reveal a creative and communicative capacity in the child that is often not evident in other settings" (McFerran \& Shanahan, 2011, p. 104). One study suggests that musical improvisation can be used to support the development of communication while also being a form of communication in itself (Perry, 2003). "For children with pre-intentional communication, musical interaction provides a framework for the communication partner to sustain interaction" (Perry, 2003, p. 243) and practice new communication skills repeatedly, within fun and engaging activities (McFerran \& Shanahan, 2011; Perry, 2003).

Similarly, social and behavioural goals have continued to be common foci for music therapists in the special education sector. It is noted that music making is, at its core, a social endeavour and therefore "can play an important part in promoting interpersonal skills, teamwork, and co-operation" (Gooding, 2011, p. 442). Music therapy then, has the ability to work towards these and other social and behavioural goals within the confines of a musical relationship (de Mers, Tincani, Van Norman, \& Higgins, 2009). A study examining the effects of music therapy for young school children with challenging behaviours found that while receiving music therapy, a decrease in negative behaviours and an increase in positive behaviours were observed (de Mers et al., 2009). Moreover, it was also noted that these outcomes were seen within the classroom as well as within music therapy sessions, suggesting that students are able to transfer their learnt skills and behaviours to situations outside of their original context. In another recent study, students with social skill deficits were found to improve social functioning and on task behaviour, and to decrease in antisocial behaviours after receiving music therapy (Gooding, 2011). A number of other pieces of literature argue similarly, stating that music therapy 
interventions have the ability to foster increased social skills and positive behaviour for school children with special needs through engagement in musical activities and music making (Daveson \& Edwards, 1998; Foran, 2009; Pellitteri, 2000; Pienaar, 2012; Rickson \& McFerran, 2007).

While the literature shows that music therapy is a promising intervention for students with special needs and disabilities to develop a range of non-musical skills, McFerran \& Shoemark (2013) re-emphasise the importance of establishing collaborative relationships through and in music, especially for those with high or very high complex special needs. Although developmental milestones will most likely continue to be at the forefront of educational goals for this population group, it is suggested that meaningful relationships are an "achievable and important focus, both within and beyond the school context" (McFerran \& Shoemark, 2013, p. 2) and therefore should be given primary focus.

\section{Key Competencies - History and Implications}

The five key competencies came into effect as an integral part of the NZC in 2007 after the Ministry of Education undertook a four year redevelopment of the curriculum, aiming to "focus on quality teaching and empowering schools to meet the needs of all students" (Rutherford, 2004, p. 1). The NZC's shift away from the previous 'essential skills', towards the key competencies was highly influenced by an international project that outlined what is needed to attain a "successful life and well functioning society” (Rutherford, 2004, p. 1) - the OECD's 'Defining and Selecting Key Competencies' (DeSeCo) project. After a period of reworking the OECD's key competencies to reflect and fit alongside the NZC and the diversity of the country, "five overarching and interconnected key competencies" ( $O^{\prime}$ Connor \& Dunmill, 2005, p. 1) were established - Thinking, Using Language, Symbols \& Texts, Managing Self, Relating To Others, and Participating \& Contributing (Ministry of Education, 2007). These key competencies create a holistic concept, integrating the previous focus on skills with knowledge, attitudes and values (Brewerton, 2004; 
Hipkins, 2006; Rutherford, 2004) to offer "a mature concept that encompasses all the components needed for effective performance or meeting the demands of a task" (Rutherford, 2004, p. 3).

'Key' competencies are explained as "those competencies needed by everyone across many life contexts to meet important challenges" (Rutherford, 2004, p. 2). These are different from 'specific' competencies, which are limited to one or a small number of contexts (Rutherford, 2004). However, the key competencies are "not separate or stand-alone" (Ministry of Education, 2007, p. 12) and do not substitute specific competencies or knowledge (O'Connor \& Dunmill, 2005). They are to be used in combination with other competencies depending on the task at hand (Rutherford, 2004). This shift towards 'universal' key competencies (Hipkins, 2006) reflects the Ministry of Education's initiative that aims to see student's become 'lifelong learners' (Hipkins, 2006; Ministry of Education, 2005, 2007), encouraging them to develop the competencies they need in order "live, learn, work, and contribute as active members of their communities" (Ministry of Education, 2007, p. 12).

Unlike the 'essential skills' which were seen as 'add-ons' placed at the end of each learning area (Brewerton, 2004; Hipkins, 2006), the key competencies are able to "integrate all aspects of learning" and "offer an alternative way of viewing [the] curriculum and a clearer focus for teacher practice" (Ministry of Education, 2005, p. 2). "The key competencies and the eight essential learning areas interweave to build the strong pathways needed for student success in learning" (Ministry of Education, 2005, p. 3). While the key competencies reflect the importance of knowledge, skills, attitudes and values in all of the curriculum areas (Hipkins, 2006), they also work to align more closely with early childhood and tertiary sectors (Hipkins, 2006; Ministry of Education, 2005). This is important as the development of the key competencies begins in early childhood and continues into adulthood (Ministry of Education, 2005). Thus, the key competencies work to set a clear direction and progression of learning, linking the sectors together to give students the needed experiences and learning to succeed in life. They also potentially provide a framework and a sense of 
continuity for working in schools with students whose developmental age might be at the early childhood level.

\section{Key Competencies and The Arts}

Dance, drama, music (sound arts) and the visual arts are the four disciplines defined in the NZC to create a bigger learning area - the arts. Within these four disciplines, students learn to express and interpret ideas (Ministry of Education, 2007; O'Connor \& Dunmill, 2005) while building on "skills, knowledge, attitudes, and understanding" (Ministry of Education, 2007, p. 20). A "unique thinking process" (O'Connor \& Dunmill, 2005, p. 2) is said to underpin the arts, encouraging students to "communicate and interpret meaning in the arts disciplines" and develop their "arts literacies" (O'Connor \& Dunmill, 2005, p. 2). It is noted that participation in and development of this learning area increases student wellbeing and builds students' confidence as risk-takers - results that go far beyond the classroom (Ministry of Education, 2007). Specific links between the five key competencies and the arts empower educators to provide "meaningful contexts for the learning of key competencies" (O’Connor \& Dunmill, 2005, p. 1).

O'Connor \& Dunmill (2005) state that the arts promotes the development of the key competency Thinking, providing students with a unique process that produces "cognitive, emotional and sensory forms of thinking" (O'Connor \& Dunmill, 2005, p. 3). The arts require students to use creative thinking to express themselves, reflect on and respond to the world, and communicate and interpret sound, movement and images (Ministry of Education, 2007; O’Connor \& Dunmill, 2005). Eisner (2002) suggests that complex modes of thinking are required when engaging with the arts, which therefore have the potential to create an environment filled with opportunities to develop and use such thinking processes. In this way, the key competency of Thinking is also being developed in such an environment. 
Using Language, Symbols \& Texts is central to all four art disciplines, because students use specific sounds, movements and images to represent, express and make meaning of their emotions, ideas, and personal and cultural identities (O'Connor \& Dunmill, 2005). A study exploring links between music therapy and the key competencies suggests that creative music therapy processes such as "composing a riff on the guitar, [or] assuming a leading role as rhythm-keeper in a group improvisation" (Halligan, 2012, p. 40) have the potential to allow and encourage unique, meaningful expression of self. Eisner (2002) agrees, stating that opportunities for creative processes through the arts not only encourage expression but impact on student wellbeing by developing freedom, flexibility and personal growth.

Managing Self is required when making sense of the 'chaos' that comes from life in order to organise and produce a piece of artistic work. While producing such works, students also manage their own development of a number of skills, including "auditory and visual discrimination, fine motor skills, [while gaining] a sense of personal accomplishment, reward, well-being and high levels of enjoyment" (O'Connor \& Dunmill, 2005, p. 7). The freedom of expression offered within the arts also has the ability to subsequently develop resilience - an aspect of Managing Self enabling students to face new challenges and adapt to new situations outside of the arts classroom (Eisner, 2002). Similarly, Nelson (2010) states that arts therapies have the potential to assist the development of coping skills and positive decision-making as self-esteem is promoted.

Although art can be produced individually, the interrelating that happens as people begin to share and communicate their feelings and ideas during collaborative efforts is directly linked to the key competency Relating To Others. Community music therapy seems to directly link with this competency as one of its' primary foci is the creation of music within communities and therefore requires collaboration and working with others. Rickson \& McFerran (2014) describe one such collaboration between an orchestra and a group of students with very high special needs who together put on a musical performance within their community. Not only did these 
two diverse groups need to musically express themselves, negotiate and interact with each other, but they had to consider the best way to fully engage the audience and communicate effectively with them.

The arts create a relaxing environment, where people can feel accepted as their true self and the teacher-learner hierarchy is often eliminated as all parties learn and create as a cohesive team ( $\mathrm{O}^{\prime}$ Connor \& Dunmill, 2005). Thus, 'cooperative learning' (O'Connor \& Dunmill, 2005) is an important feature of the arts. It encourages active participation as everyone works together to create and perform, supporting a "positive, reflective, appreciative environment where all contributions are accountable to the communal outcome" (O'Connor \& Dunmill, 2005, p. 7) - a true reflection of Participating \& Contributing.

Eisner (2002) states that "experience in the arts develops initiative and creativity, stimulates the imagination, fosters pride in craft, develops planning skills, and in some arts fields helps the young learn how to work together" (p. 33). These links show the rich context that these four disciplines provide. The arts can create many opportunities for the development of all five of the key competencies as both students and teachers engage in and with the arts.

\section{Summary}

While there is only a small amount of literature written about music therapy within education compared to the ever-growing number of music therapists working in this sector around the world (Tomlinson, Derrington, \& Oldfield, 2012), the literature that is available states that the potential benefits are evident among this population group. Music therapy and special education in New Zealand are both underpinned by a holistic philosophy with a focus on student wellbeing and the realisation of students' potential. It therefore seems appropriate that music therapists work in this field, supporting the work of other professionals by focusing on non-musical goals within the confines of a musical and therapeutic relationship. The key competencies 
reflect more broad capabilities needed in a range of contexts in order to live, learn and participate as part of the community - competencies that may be extremely important for students with high or very high complex special needs in order to live and participate in society to the best of their ability. The arts clearly provide a context that encourages students to develop the five key competencies outlines in the NZC, suggesting that music therapy too has this ability. This leads to my research question; how did I support students with high or very high complex special needs to develop the key competencies outlined in the New Zealand Curriculum? 


\section{METHODOLOGY}

\section{Overview: Methodology and Approach to Research}

In this qualitative study I took clinical data produced as part of my music therapy practice and reviewed it in order to find out how my music therapy practice linked to the key competency framework. This methodological process is known as secondary analysis of data. Qualitative research seeks to discover meaning (Wheeler, 2005) in order to "enlarge constructions of the world and to find and create individual meanings therein" (Bruscia, 2005) through the use of rich, descriptive data. Secondary analysis was employed as both the methodology and method (Heaton, 2008). It is a process that reuses and reanalyses old or pre-produced data in order to answer a new question and develop new understanding (Glass, 1976; Heaton, 2008; Irwin, 2013). No participants took part in this study as the data was originally produced for the purpose of my clinical practice and then 'reused' in this study for a second purpose. This reanalysis of self collected data (Heaton, 2008) aimed to uncover new context derived meaning and "descriptions of phenomenon that make sense from the inside and are palpable to the outside" (Wheeler, 2005, p. 59).

\section{Theoretical Framework}

Qualitative research is undertaken when researchers want to create and explain new meaning within a context in order to answer a pre-existing or new research question (Wheeler, 2005). This study employed a constructivist perspective as the underpinning theoretical framework. Constructivists understand that knowledge and reality are subjective (Edwards, 1999) and Potter (1996) supports this stating that "the world is subjectively constructed by the meanings that people assign to observations" (p. 40), each new meaning shaping ones perspective and reality of the world. Therefore, knowledge is socially constructed and context bound, unable to be understood without reference to that context (Edwards, 1999). This qualitative study aimed to find "pattern theories" (Edwards, 1999, p. 76) within the data that come 
together to make or construct meaning that agrees with or disputes previously constructed knowledge.

\section{Method and Design}

"Qualitative research methods involve the systematic collection, organisation, and interpretation of textual material derived from talk or observation" (Malterud, 2001, p. 483). It was therefore important to employ a systematic and rigorous method and design when undertaking this study in order to gather and analyse data in a meticulous fashion. Secondary analysis was utilised as the method of data collection and analysis in this qualitative study. Following this method, pre-existing data that was originally generated for my clinical practice was collected and used for a second purpose - to find the techniques and strategies that supported the key competency framework.

\section{Data Analysis}

The data used in this qualitative study was produced as part of my clinical practice for the purpose of keeping a record of sessions, student engagement and progress, and ultimately to improve my practice. Due to the large amount of data collected, it was decided that only a portion of the data would be used for research purposes in order to fit within the means of the study. Data from the beginning of my placement was omitted and a ten-week block of individual music therapy session with eight students from my second term at the school was chosen for analysis.

In the initial stage of analysis, each student's music therapy goals were analysed deductively and links were made to the five key competencies, with reference to the Key Competencies Pathway document (KCP Curriculum Group, 2012). Students' data sets were placed into the categories/key competencies that their goals related to. For example, if a student's goal linked to Using Language, Symbols \& Texts and Relating To Others, that student's entire data set was placed into both the Using 
Language, Symbols \& Texts category and the Relating To Others category. During this initial process, I was aware that categorising the data in this way was in reality not this clear cut. However, this seemed to be the most pragmatic and effective system of sorting the data before beginning thematic analysis.

Once the data was sorted into categories I read and re-read the data within each category to get a sense of the data as a whole before beginning analysis. I used a process of thematic analysis to code and find common themes or patterns within the data (Braun \& Clarke, 2006; Vaismoradi, Turunen, \& Bondas, 2013). The four steps described by Vaismoradi, Turunen \& Bondas (2013) were used as a guide during this process: generating initial codes, searching for themes, reviewing themes, and defining and naming themes.

- Firstly, I searched through the data, underlining and initially coding any techniques or strategies I had used that supported that category's key competency in order to generate my initial codes (see Appendix 1). Code names were selected that succinctly described my actions. Each category's codes were then put into a spread-sheet and sorted, allowing me to review the initial codes, merging codes that were closely related and re-coding others to more accurately describe the technique or strategy used (see Appendix 2).

- After initially coding the data, I began searching for emerging themes within each category (see Appendix 3). Codes were gathered together where broader links seemed to appear and larger themes began to emerge.

- The themes were then reviewed and revised, re-naming and moving codes to create more succinct and clear themes where needed.

- Finally, themes were named and defined in order to produce clarity of understanding within each category before writing up the Findings section that follows.

A combination of deductive and inductive modalities were utilised during this analysis process (Braun \& Clarke, 2006; Vaismoradi et al., 2013). The former was 
used in the initial stages of analysis in order to fit the data into the five categories relating to the key competency framework, and a combination of the two were used to find the arising themes within each category. These rigorous qualitative methods worked together with the aim to construct meaning and understanding by revealing the links between my music therapy practice and the key competency framework within the data.

\section{Ethical Considerations}

This qualitative study utilised a method of secondary analysis, using pre-produced data for a secondary purpose. For this reason, no direct participants were involved in this research project and it was considered a low risk study for both students and the school. Despite this, there are some ethical considerations worth noting here.

Firstly, while I was undertaking my clinical work, I was aware that I would eventually want to review my data for research purposes. Due to the nature of this study, it was imperative that the data being analysed was produced in a naturalistic way, solely for its original purpose. When collecting my data I endeavoured put aside my research hat and focus solely on the clinical work at hand as I facilitated music therapy sessions and wrote up my notes.

Confidentiality and anonymity was another important factor in this study in order to uphold the students, their families and the schools rights of privacy and security. Key identifying information was therefore removed. Data that contained information about specific students and music therapy sessions was kept on password-protected computer both at the school and off site in order to ensure its security. Viewing of the data was restricted to those with permission, including school personal, students' family members, and current staff and students at the New Zealand School of Music as agreed to by the school. 
Informed consent was requested and gained from the school as a whole in order to obtain permission to re-use the collected data for the purpose of this study (see Appendices 4 \& 5). Where a student was directly implicated in this study (e.g. in the vignette which is included in the findings), informed consent was also gained from that students' family (see Appendix 6, 7 \& 8). Consultation with a Maori adviser was used as a way of ensuring that Maori views and culture were considered and respected at all times during the research process. The NZSM Music Therapy Programme Leaders have sought and gained ethical approval by the Massey University Human Ethics Committee for music therapy students undertaking research of this kind (HEC: Southern Application - 11/41). 


\section{FINDINGS}

\section{Overview}

The findings that follow provide a description of the techniques and strategies used during the analysed music therapy sessions in order to answer the research question - how did I support students with high or very high complex special needs to develop the key competencies outlines in the New Zealand Curriculum? A number of musical, physical and verbal techniques were used that supported the development of the five key competencies. What follows is a concise description of each category or key competency, followed by the techniques and strategies that supported and encouraged the development of specific aspects or skills within that key competency. I begin with Thinking because it underpins the other four (Hipkins, 2006). A vignette is then presented, describing a music therapy session with one student. This offers a rich and clear description of the many techniques and strategies utilised within a music therapy session and how they supported the development of the five key competencies.

\section{Thinking}

"Thinking is about using creative, critical, and metacognitive processes to make sense of information, experiences and ideas. These processes can be applied to purposes such as developing understanding, making decisions, shaping actions, or constructing knowledge" (Ministry of Education, 2007, p. 12). For students working at level one of the NZC, Thinking requires an understanding "that learning makes sense of our world and exploring it in different ways is rewarding" (KCP Curriculum Group, 2012, Thinking section). Encouraging students to actively seek knowledge by exploring and showing an interest in the world around them is therefore important and an integral part of learning and living. 
When analysing the data, only one student was found with a goal that seemed to relate solely and directly to Thinking. However, I was also aware that Thinking underpins the other four key competencies and was therefore being reinforced even when it may not have been the primary focus of the work. A range of musical techniques and strategies were found that were used within music therapy sessions that encouraged and reinforced the students' interest in and exploration of their world through music - skills that are needed in order to actively seek knowledge. The data revealed that familiar language was presented in the form of lyrics within familiar music. In many instances I used familiar music to create a recognisable and therefore relaxing environment where the student would be comfortable and more inclined to take an interest in, examine and gain knowledge of the environment around him. Familiar music was also used to calm the student in order to allow him to engage with and explore a range of instruments. In one session where the student became upset, I began to sing a familiar song in a slow, legato tempo while moving the student's hands gently up and down in time with the music. In doing this, I was attempting to create a calming environment and refocus the student's attention to the music so that he was able to re-engage, take an interest in the music and explore his world.

The student's exploration of instruments and his voice was reinforced and encouraged when I matched or copied his mood, movement, playing or vocalisations as we improvised. For example, in one session when the student vocalised a long 'ah' sound, initially quietly then gradually increasing in volume, I copied his vocalisation directly after he had finished, matching his pitch and dynamics with my voice and guitar playing in order to reinforce his use and exploration of voice and to encourage further vocalisations. This technique is based on the idea that participants hear and recognise themselves as an integral part of the music. When students recognise themselves in the music self-understanding increases and they are better positioned to explore their word. Lyrical affirmation further supported this idea when I improvised lyrics in song, acknowledging and affirming the student's interest in and exploration of instruments and sounds. The student was encouraged to begin or continue to explore and engage in the music through instrument playing as I 
introduced a new sound, left space in the music, held chords, or sang the students name. In one session where the student's interest seemed to have waned, I left a space in the music by holding the dominant $7^{\text {th }}$ chord in order to create a sense of suspense and encourage him to re-engage in the music making. After a few seconds of holding the chord, he began to vocalise, becoming louder as he became increasingly excited.

Not only were singing the student's name, using familiar language and lyrical affirmation used musically to encourage the student to be interested in and explore his world, they were also considered verbal techniques and strategies that further support Thinking.

\section{Using Language, Symbols \& Texts}

"Using language, symbols and texts is about working with and making meaning of the codes in which knowledge is expressed. Languages and symbols are systems for representing and communicating information, experiences, and ideas. People use languages and symbols to produce texts of all kinds... Students who are competent uses of language, symbols and text... recognise how choice of language, symbol or text affects peoples understanding and the ways in which they respond to communications" (Ministry of Education, 2007, p. 12). During the early stages of developing this competency, students learn to work with language, symbols and texts to "convey meaning by using specific words, symbols, images, sounds, movements and/or technologies" (KCP Curriculum Group, 2012, To Work With Language, Symbols and Text section) in order to express themselves.

Six of the eight students whose data was analysed in this study had goals relating to Using Language, Symbols \& Texts, which emphasises the importance of its development for students with high or very high complex special needs. Various musical techniques and strategies were used that supported the use of language, symbols and text in order to convey meaning and express ones self, predominantly 
through the use of music (sound) and verbal language during music therapy sessions. Like Thinking, familiar language and familiar music were used in conjunction with songs in the students' first language to create a relaxed and familiar atmosphere were students could feel comfortable to express themselves through music and verbal language. The repetition provided through the familiar language and music gave students a greater potential to use, or at least try to use that language and music themselves. Introducing new sounds presented students with a range of new sounds to respond to and make meaningful music with, ultimately increasing their sound 'vocabulary' for future music making and communication.

The data also showed that modelling verbal language, symbols and alternative communication devices demonstrated the use of specific words or specific ways of communicating. For example, when using two switches ${ }^{5}$ with a student to make the music 'stop' and 'go', I initially modelled their use by pressing the 'stop' switch myself and at the same time stopping the song that I was playing. This modelled where the switches were and how to use them, and also demonstrated the meaning of the word 'stop' by stopping the music. Later in the session, the student was able to use the switches on her own to say 'stop' and 'go' and, as a result, control the music. Changing dynamics and tempo were used independently and at times in conjunction with holding chords/notes, leaving space in the music, pausing, giving lyrical instruction and singing the students' names, either in response to the students' uses of language, symbols or texts or to encourage students to express themselves through verbal language, vocalisations, music making or sound. In one session when a student had stopped playing and vocalising for an extended period of time, I encouraged him to use sound (instrumental or vocal) to re-engage in the musical 'conversation' by holding one of the chords in the song and decreasing my guitar volume to match his mood before gradually increasing the volume again.

Students were at times encouraged, through lyrical choice, to use sound and language without expectation in order to express themselves how and as they

\footnotetext{
${ }^{5}$ A switch is a communication device used to communicate a simple message, often used to answer a question, participate an activity or affect a situation.
} 
wanted. For example, during a number of sessions with one student, I emphasised his choice to use sound in this way by singing "play what you wanna play", giving him choice and control over when and how he wanted to contribute to the music. Action songs supported students' understanding of words and their corresponding meanings by encouraging them to complete actions independently or with physical support as they were sung. Hand-over-hand was the main way that physical support was given in order to create these linguistic connections, while also being used as a support when students were unable to play instruments independently.

Students' use of language, symbols and texts were reinforced when I copied their playing and vocalisations, reaffirming their use of sound by repeating it back to them. Similarly, matching mood, movements, playing and dynamics reinforced students' use of sound, movement and mood to convey meaning and express themselves by interpreting and representing their contributions in my music. For example, while singing our hello song, one student began to smile and move her body back and forward excitedly. In response, I began to increase my volume and strum the guitar faster to match her movements and mood, letting her know that I had seen her way of communicating that she was enjoying the music. Lyrical affirmation offered additional confirmation of students' use of language, sound and movement as they expressed themselves by verbally declaring what they were doing. In this way, students' use of sounds, verbal language, movement and mood often created the basis for further improvisation, beginning a back and forward exchange where I would follow the students' lead to encourage additional use of sound, verbal language and movement and the expression of a musical conversation.

The findings showed a crossover between many musical and verbal techniques and strategies that encouraged the use of language, symbols and texts, with a few additional verbal techniques. Singing the students' names, using familiar language, using songs in the students' first language, lyrical choice, lyrical instruction, copying vocalisations, lyrical affirmation and modelling were categorised as musical techniques and strategies, as they were used as part of the music making process. However, these practices contain verbal aspects, either verbal language or sound, 
and therefore have also been placed in the 'verbal' category. Verbal greetings were used in many music therapy sessions and engaged students in typical social interactions through the medium of verbal communication, modelling how to use language appropriately to communicate with one another. I used words in the students' first language as well as songs, where it seemed appropriate, to engage students through potentially more familiar language that they may have understood more easily than English. In doing this, students were presented with another language that they could use to communicate and convey meaning. For example, when singing a hello song with one student, I paused to leave a space for him to reply to my verbal greeting. When he did not initially reply, I said hello to him in his first language to further encourage him to say hello in reply.

At times I verbally directed students' use of language, symbols and text by asking direct questions and encouraging them to verbally reply, giving verbal prompts to further motivate their use of verbal language. Verbal instruction was used to explicitly direct students' use of language, sound or music. For example, in one session in the middle of a song I paused to leave a space for the student to say the word 'go'. After a few seconds, where the student was sitting still in his chair listening, I gave a verbal prompt by saying 'ready' to which he enthusiastically replied 'go'. Students' use of verbal language was reinforced by verbal affirmation repeating what the students had said or verbally acknowledging their use of language. Repetition was also used during music therapy sessions and gave students a number of opportunities to practice using their verbal language while the music motivated and engaged the students.

Physically, students were encouraged to use language, symbols and texts when I positioned/repositioned instruments so that they were able to produce sound more effectively. The use of action songs enabled students to gain understanding of the meaning of words within songs, while hand-over-hand was used to help make the connections between actions and words and help students to play instruments when they were unable to do so independently. When students used physical movements 
as an avenue for communicating, they were reinforced through copying and matching their movements both physically and musically.

\section{Managing Self}

Managing Self "is associated with self-motivation, a 'can-do' attitude, and with students seeing themselves as capable learners. It is integral to self-assessment. Students who manage themselves are enterprising, resourceful, reliable, and resilient" (Ministry of Education, 2007, p. 12). Managing Self encourages students to act independently by completing and participating in a range of activities by themselves, and requires them to use their initiative in a range of familiar and unfamiliar situations. Meeting challenges is also important for students working at level one of the curriculum as they learn to manage their emotions and behaviours (KCP Curriculum Group, 2012).

Physical goals were common among the students involved in this piece of research due to the school's requirement that prospective students must have a severe physical disability in order to be eligible to enrol. For this factor alone, it was not surprising that seven of the eight students' goals linked to Managing Self, six of them working towards becoming more physically independent, and two students' goals relating to 'managing my emotions'. Musical techniques and strategies were found within the data that encouraged independence and the managing of emotions. Familiar music was found to encourage students to contribute to the music by playing an instrument independently. Changing dynamics, tempo and style of playing were used at times in an attempt to calm the students and encourage them to manage their emotions when they became overly excited. At other times these techniques encouraged students to participate in and/or initiate an action in the music making process independently. For example, when one student had stopped playing the chimes I changed my guitar playing style from using soft, legato chords to a more energetic staccato rhythm to encourage him to independently manage himself and lift his arms again to play the chimes. Similarly, I held chords, left space 
in the music, introduced new sounds, and sung students' names to nonverbally support them to autonomously complete actions and play their instruments. Lyrical choice was given to encourage students to initiate playing and act independently. Completing movements autonomously was further supported and directed through the inclusion of action songs in music therapy sessions.

Independence and participation were reinforced when I copied students' playing and vocalisations, and matched their moods, movements and playing. When one student initiated playing the keyboard by hitting her flat hands loudly on the keys, I acknowledged and reinforced her independence and participation by copying her playing and hitting my hands loudly on the keyboard in the same manner. The student clearly recognised my support as she smiled, laughed and hit the keyboard again. Lyrical affirmation was also used to promote students' independent actions and participation, alongside following the students' lead and using repetition to reinforce Managing Self.

Physically, students were encouraged to act independently as I positioned and repositioned instruments so that they had the greatest chance of being able to play them autonomously. Managing Self was also reinforced physically when I copied and matched students' movements, and following the students' lead as a way of acknowledging and applauding them for acting independently and using their initiative. The use of action songs encouraged students to manage their physical bodies by completing the corresponding action sung in the song, while hand-overhand physically supported students to complete either body movements or instrument playing when this could not be achieved independently. Modelling was sometimes used to demonstrate how to complete a task, such as pushing a switch to contribute to the music.

Verbal encouragement of Managing Self was found when I sang students' names and used songs in the students' first languages. This use of verbal language may act to reinforce and further strengthen the support provided by the music, working together to create a stronger force of encouragement to act independently. Verbal 
and lyrical affirmation worked in the same way, to ratify students' physical actions verbally and lyrically, when they are able to manage their actions. Direction was given through verbal prompts in order encourage physical movements and give students the best chance of being able to complete those actions with as little physical support as possible.

\section{Relating To Others}

"Relating to others is about interacting effectively with a diverse range of people in a variety of contexts. This competency includes the ability to listen actively, recognise different points of view, negotiate and share ideas. ... [Students] are aware of how their words and actions affect others" (Ministry of Education, 2007, p. 12). In order to successfully interact with others, students must be able to express themselves, their feelings and ideas, and learn from and with the people around them (KCP Curriculum Group, 2012). This is accomplished by maintaining interactions with others as the basis for building relationships.

Four of the students' data in this study had goals specifically linking to Relating To Others. Like Using Language, Symbols \& Texts, expressing one's self was a focus for three of the four students' data analysed in this category. In order to do this, students were learning to express their feelings and ideas while displaying selfconfidence. Learning from and with others, specifically building relationships through interaction with others was the focus of the fourth student in this category. Musical and verbal techniques and strategies were found within the data that supported Relating To Others. Familiar music was yet again used, creating a comfortable environment to allow students to interact with me effectively within the music. Similarly, instruments were repositioned to allow students to play them most effectively and intentionally in order to meaningfully express themselves and be a part of and contribute to the musical relationship. In many music therapy sessions, I changed dynamics, held chords, introduced new sounds, left space in the music, paused, and sung the students' names in an attempt to calm students and to 
encourage them to communicate their feelings and ideas with me. For example, after one student had been listening to me play a song for a few minutes, I held a chord in the song at the end of a phrase to encourage him to play and to give him space to express himself by either lifting his hands to play the chimes or by vocalising. After a few seconds he began to vocalise loudly while smiling and moving his body excitedly. A session with a different student displayed my use of singing a student's name to encourage self-confidence and initiation of expression. During the first half of the session, the student had stayed sitting in her chair with her hands on her lap, smiling as I sang songs and played music in an attempt to encourage her in our musical relationship to engage in the music making process with me. She happily stayed in this position until I began to sing her name, at which stage she laughed hysterically before reaching out towards the keyboard and hitting the keys with enthusiasm in what seemed to be her expression and response to my singing. Alongside these techniques and strategies, I offered lyrical choice to further encourage interaction and expression of preference. With another student I used lyrics to encourage him to use his voice to sing along if he wanted to by singing "sing along if you feel that's what you wanna do". This gave him the choice to express his wants by allowing him to make the decision to engage vocally if he desired to.

Students' efforts to interact with me were musically reinforced when I copied students' playing and vocalisations, and matched their mood, movements and playing. For example, when one student played the keyboard confidently after I had lyrically encouraged her, I reaffirmed her musical interaction with me by copying her playing within the song while giving her further support by looking at her and smiling. Repetition and lyrical affirmation were the final techniques and strategies found that reinforced students' expression and interaction with me, and the development of Relating To Others through the musical relationship.

A portion of musical techniques and strategies were also categorised as being verbal, with singing students' names, and giving lyrical choice and affirmation all containing an aspect of verbal language. The data also showed a few techniques and strategies that were solely verbal. During music therapy sessions I asked direct questions, 
demonstrating an initiation of interaction with the students, while directly giving them an opportunity to express their wants, likes and dislikes. For example, after introducing the lollipop drum to one student by playing it myself, I them asked him if he would like to play it himself, giving him an opportunity to voice his opinion and express himself. He immediately smiled and vocalised enthusiastically, conveying the message that he did indeed want to play the drum. Verbal prompts were also used within sessions to encourage expression of self and relationship building, while verbal affirmation was used to reinforce expression and interaction with me.

\section{Participating \& Contributing}

Participating and contributing "is about being actively involved in communities. Communities include family, whanau, and school and those based, for example, on a common interest or culture. ... This competency includes a capacity to contribute appropriately as a group member, to make connections with others, and to create opportunities for others in the group. Students who participate and contribute in communities have a sense of belonging, and confidence to participate in new contexts" (Ministry of Education, 2007, p. 13). Students are required to develop confidence in order to try new activities and participate in different communities. Responding to questions that influence the group and empower students to exercise their rights and contribute ideas as a valued member of a group are skills that are incorporated in this key competency (KCP Curriculum Group, 2012).

Similar to Thinking, the data revealed that only a few students' goals linked to Participating \& Contributing, with only two students' data sets being analysed in this category. Participating \& Contributing was supported through a range of musical, verbal and physical techniques and strategies in order to encourage confidence to participate in and contribute to the music and musical direction. Familiar music and repetition worked to calm students by establishing a familiar, comfortable environment for students and support them to confidently participate in and contribute to the music and its direction. For one student, a familiar hello song was 
used at the beginning of every session to give her a sense of familiarity, to attempt to calm her fears of the unknown and to build her sense of confidence in order to participate in the music and contribute to the session through her playing. Changing dynamics, holding chords, pausing, singing students' names, leaving space in the music and giving lyrical choice worked to encourage students to participate in, and contribute to, a particular moment in the music. Participation in and contribution to the music making was reinforced as I matched students' mood and playing, and copied their playing and vocalisations. Lyrical affirmation and following the students' lead were also used during music therapy sessions, praising students as they chose to participate in and contribute to the music. For example, when one student clearly pointed to the chimes that were a metre away from her, I affirmed her choice of instrument by following her clear attempt to communicate and brought the chimes to her so that she could play them. In this way she had made a direct communicative gesture that contributed to the direction of the session. In response, the student immediately reached out and played the chimes with great excitement, hitting them loudly and laughing as I lyrically sung about her playing.

Verbal support that encouraged participation and contribution during music therapy sessions was given when I initiated conversations, gave lyrical choice and sung the students' names. Students were also supported to develop this key competency as I directed and instructed their participation and contribution by asking direct questions, verbally prompting and verbally instructing them to complete specific tasks. For example, after finishing one activity with a student I verbally asked him if he would like to play the keyboard next, giving him a clear opportunity to exercise his rights as a part of the 'group' and affect the direction of the session. He smiled and vocalised excitedly, which was his way of communicating that he certainly did want to play the keyboard. Lyrical and verbal affirmations were used musically and verbally, respectively, to reinforce students' participation and contribution within musical relationship. One physical strategy, repositioning instruments, was used in this category to give students optimal opportunity to successfully participate and contribute to the session musically. 


\section{Clinical Vignette}

I first met Ben, an 8-year-old boy with cerebral palsy, during my initial week of placement at the school and started working with him in individual music therapy sessions a few weeks later. Ben was in a wheelchair as he had severe contractures in his muscles with associated limited movement. At times his muscles contracted so badly that he became extremely straight and stiff, to the point where he was unable to use his limbs for a period of time, until his muscles loosened again. He also had difficulty controlling the muscles in his face and mouth, restricting his expressive language. He was therefore mostly non-verbal, although he was able to offer vocal approximations of a few key words. He was able to clearly express basic wants, needs and feelings to those around him by using a combination of vocalisations and facial expressions. His receptive language, on the other hand, appeared to be good and it seemed that Ben was able to understand everything that was said to him. Ben also had a cerebral visual impairment (CVI), and thus seemed to rely mostly on auditory information to make sense of the world.

It was suggested that Ben would be a good candidate for individual music therapy sessions with me as he loved music and was known to laugh, smile and vocalise a great deal during group music therapy sessions. Music was highly motivating for Ben and music therapy could potentially support him to practice a range of non-musical skills while participating in something that he enjoyed. This vignette describes our $11^{\text {th }}$ music therapy session together. Here we were working on three goals taken from Ben's IEP: to respond verbally (specifically the words 'yes', 'no' and 'more'); to independently open his fingers for a functional purpose; and to hold his head up for 30 seconds. These goals were also being worked on with other members of staff throughout the school day and so I was able to reinforce them during our time together. 
I met Ben in his classroom, as was our typical routine, to take him to the music room for our session together. Ben had just finished a swimming session and seemed quite tired as he was finding it difficult to hold his head up against his headrest. I had to verbally remind him and at times physically help him to lift his head up throughout the session. Once we had arrived in the music room, I began to play and sing our usual opening song, our hello song, and Ben listened. After I had sung hello to Ben, I softly held the final chord of the phrase, leaving a space in the music for him to respond and say hello using his voice. He initially stayed silent until I prompted him further by gently saying, 'Are you going to say hello, Ben?' In his typical style, Ben smiled and vocalised 'ah' enthusiastically before I continued playing to the end of the song.

After finishing our opening song, I asked Ben if he would like to play the chimes. He immediately smiled and vocalised 'ah' in an excited manner, which I interpreted as a clear way of communicating that he did indeed want to play the chimes. I prompted him further to use his words by saying 'was that a yes, Ben? Yes!' to which he vocalised 'ah' again. To reinforce his decision, I moved the chimes in front of him and he immediately lifted his hands excitedly towards the chimes - an action that further emphasised his earlier vocalisations. I began to energetically play the chords to Upside Down by Jack Johnson on the guitar to match Ben's excitement, a song that I had played in previous sessions with Ben. I initially omitted singing the lyrics at the beginning of the song and instead chose to solely play the chords on the guitar in order to give Ben space to play, waiting to see what he would do. Ben lifted up his hands sporadically to play the chimes which I emphasised by slightly by playing slightly more staccato chords on the guitar, before I began to sing, 'stretch out your hands, Ben. I want to hear you play!' - lyrics that I had sung during a previous music therapy session to encourage Ben to lift his hands. He smiled broadly and laughed while lifting his hands excitedly to play the chimes as I sung and I again matched his play with slightly more staccato chords. We continued to play together and I followed Ben's lead, improvising lyrics that reaffirmed his actions such as lifting up his hands and looking at the chimes. At different points throughout the piece Ben seemed to have stopped playing and I began to hold a chord, typically the dominant 
$7^{\text {th }}$ chord, starting quietly and gradually getting louder in order to create a feeling of suspense and encourage Ben to play again. This was usually successful, with Ben vocalising, laughing and/or lifting his hands to play the chimes until he seemed to have come to an ending point and I finished the song. After finishing the song I asked Ben if he would like to play more chimes or to play something else. This gave him an opportunity to influence what was going to happen and to practice his verbal responses. Ben quickly vocalised 'ah' and smiled after I offered more chimes, and I encouraged him to attempt to say 'more'. After a short pause where Ben was obviously trying to make his mouth move, he successfully put his lips together in the ' $m$ ' position followed by vocalising 'oh'. This was a great accomplishment for Ben and I affirmed him by playing the guitar again. He continued to play the chimes for a few more minutes before we finished again. After pausing at the end of the song, Ben put his lips together again in the ' $m$ ' position, which I took as an attempt to ask for more, and so began to play the song one last time.

At the conclusion of the song I introduced the ocean drum, placing it on Ben's lap at a position that he could reach and began to play The Ants Go Marching. Ben, with clenched fists, lifted his hands onto the drum and I continued to play a simple 4/4 beat so that he could feel the vibrations on his hands. I then physically helped him to play the drum by using hand-over-hand - lifting his hands and lowering them to the drum on every second beat to make the drum sound. Ben laughed, smiled and vocalised as we played together and his laughter became increasingly hysterical as I sped up the song at the end of each verse and consequently helped him to drum faster. As we continued to play, I noticed that Ben's hand slowly loosened until they became almost completely flat on the drum at the end of the song. I decided to finish the session there after singing our goodbye song to Ben as it was almost time for lunch and so I took him back to his class where we said our goodbye once more.

During the process of analysing my data, I realised that I had been supporting the development of all five of the key competencies in my individual music therapy sessions with Ben. His three goals linked directly to four of the key competencies verbally responding with Using Language, Symbols \& Texts, Participating \& 
Contributing, and Relating To Others; and independently opening his fingers and holding his head up for 30 seconds with Managing Self - all four competencies underpinned by the fifth, Thinking.

Managing Self was a focus at the beginning of and throughout the music therapy session, as Ben was tired from his swimming session and consequently found it difficult to hold his head up. Verbal prompts encouraged him to manage himself and act independently in order to lift his head by himself. At times, when Ben needed further help to complete this task, I offered physical support and used hand-overhand to help him lift his head back into his headrest.

Musically, I began the session with our typical hello song, using familiar music that set the tone for the session and created a comfortable space where Ben would be more likely to use music (sound) and words to communicate (Using Language, Symbols \& Text). The lyrics in the hello song further supported Using Language, Symbols \& Text as they contained familiar language that Ben would be exposed to throughout the day. I gave Ben the opportunity to respond verbally to my greeting by leaving a space in the song, encouraging him to communicate meaningfully by using either conventional or unconventional words. A verbal prompt was then presented that directly encourage Ben to say, 'hello' ('are you going to say hello, Ben?'), which elicited a smile and enthusiastic vocalisation, 'ah' (Using Language, Symbols \& Text).

When asked if he would like to play the chimes, Ben was encouraged to use three of the five key competencies. This direct question encouraged him to Relate To Others (me) by expressing himself and his specific wants, while Contributing to the direction of the session by clearly communicating his wants with a verbal 'yes' or 'no' (Participating and Contributing). Thus, Using Language, Symbols \& Text was concurrently supported, as it became the medium through which Ben was able to contribute and express himself. Although Ben's smile and vocalisation indicated that he would like to play the chimes, I used another direct question to reaffirm his choice. My question also challenged him to clearly express his decision by 
verbalising, 'yes' ('was that a yes? Yes!'), which he vocalised as 'ah' once more and immediately lifted his hands towards the chimes as they were placed in front of him.

Ben's enthusiasm to play the chimes prompted me to accompany him with simple chords on the guitar, following his lead and leaving space in the music that empowered him to Use Language, Symbols \& Text, specifically music making, to express himself. As Ben's playing became less frequent, I lyrically instructed him by singing, 'stretch out your hands, Ben. I want to hear you play!' to encourage him to act independently and manage himself in order to play the chimes successfully. These two competencies were repeatedly supported as we improvised together, with lyrical affirmation being used to scaffold Ben's musical expression while encouraging him to continue to play and act independently ('I can hear Ben on the chimes', 'I love to hear you play, Ben'). At points where Ben's playing seemed to have faltered, a combination of holding chords and changing dynamics were used to create a sense of suspense, with the intention that he would be encouraged to gain momentum and play again. In this way his development of Managing Self and Using Language, Symbols \& Text were further supported.

The key competencies Relating To Others, Participating \& Contributing and Using Language, Symbols \& Text were reinforced when, after finishing playing, Ben was presented with a verbal question offering him a choice between playing the chimes again or moving on to something else. In doing this, Ben was encouraged to express his wants (Relating To Others) and exercise his rights by directing the session (Participating \& Contributing) through the use of words (Using Language, Symbols \& text). A verbal prompt was given to motivate Ben to attempt to say the word 'more' rather than simply vocalising (Using Language, Symbols \& Text). Ben took on this challenge and was able, with perseverance, to put his lips together in the ' $\mathrm{m}$ ' position and then, separately, vocalise 'oh'. Playing the song again reinforced his verbal answer and value as a decision-maker for the session's direction. Using Language, Symbols \& Text, Relating To Others and Participating \& Contributing were further supported when I paused at the end of the song, giving Ben space to use words and/or music to express himself and his wants, and to contribute to the 
session respectively. Taking up this opportunity, Ben quickly put his lips together to ask for more and his request was granted when we began to play once again.

The next and final musical activity focused primarily on Managing Self, with the physical support of using hand-over-hand to help Ben lift his hand and play the drum. In doing this, Ben was able to focus on relaxing and opening his fingers independently in order to play the drum more effectively without having to concentrate on lifting his arm.

Although Thinking was not a specific emphasis that underpinned this music therapy session, it supports and reinforces each of the other key competencies. Ben was required to think and use his previous knowledge to select the appropriate words and/or sounds during the session in order to communicate meaningfully by Using Language, Symbols \& Texts. Thinking was essential for Ben when managing himself in order to plan and complete physical movement independently, allowing him to play instruments and make music by himself. Relating To Others and Participating \& Contributing were both underpinned by Ben's ability to understand and specify his own wants, while realising that in expressing his ideas he was able to set the direction of the session. Thus, Thinking was continually being reinforced when any of the other competencies was being supported.

\section{Summary}

The analysis process revealed that all five key competencies were supported through the use of a number of musical, verbal and/or physical techniques and strategies within music therapy session. A range of musical techniques and strategies supported the key competency Thinking, with a small number of verbal techniques and strategies used as well. These techniques and strategies were found to stimulate curiosity by encouraging interest and exploration of the world, specifically through and within the music - skills that work towards the ability to actively seek knowledge. Using Language, Symbols \& Texts was supported as students were 
encouraged to work with and convey meaning by using language, symbols and texts in order to express themselves, their needs, wants, likes and dislikes. The data showed that a range of musical, verbal and physical techniques and strategies were used to do this, encouraging and developing expression through language, symbols or texts - or in many cases in this study - music. Managing Self was supported by a number of musical, physical and verbal techniques and strategies, many of which were used to support the previous two key competencies. These techniques and strategies encourage students to participate in and complete a familiar activity, either with support or independently, as well as initiate an action within a familiar activity or situation. These techniques and strategies also supported students to meet challenges by learning to manage their emotions. Expression of self was again supported in the third category - Relating To Others. Students were encouraged to express their wants, needs, likes and dislikes, and display self confidence by initiating self expression, as well as maintaining interactions with others in order to build relationships with others. A range of musical and verbal techniques and strategies were used when supporting students in their development of Relating To Others, many of which crossed over with the findings of the other key competencies. The development of and interaction through the musical relationship between each student and myself also seemed to be an extremely important part of supporting Relating To Others as this key competency is based around interacting with a diverse range of people. Participating \& Contributing focused on students' self-confidence in order to participate in new activities and their contribution to music therapy sessions by expressing a 'yes' or 'no' when given an option. Verbal techniques and strategies were found to mainly support the latter while a range of musical, verbal and physical techniques and strategies were used to support the former. 


\section{DISCUSSION}

The findings of this study cannot be considered alone and therefore will be discussed with reference to, and in light of, previous research and other literature. The purpose of this study was to find the techniques and strategies that I used within music therapy sessions with students with high or very high complex special needs that supported their development of the key competencies. The section that follows, aims to synthesise the findings and bring to light broader ideas and thoughts that stem from the research.

\section{The Interconnected Nature of the Key Competencies and Music Therapy}

The research findings suggest that a number of techniques and strategies used within music therapy sessions, when working towards a range of non-musical goals, were simultaneously able to support the key competences. The NZC (Ministry of Education, 2007) states that the key competencies are needed to "live, learn, work, and contribute as active members of society" but they are "not separate or standalone" (p. 12). This interconnectedness means that they are often used in combination with one another, and alongside other specific competencies (Rutherford, 2004). This supports and explains, at least in part, why the findings revealed that many of the techniques and strategies supported development of a number of the key competencies.

The activities undertaken within music therapy sessions provided opportunities for students to use all five of the key competencies in real life contexts, as they participated in sessions, worked towards their goals and ultimately enhanced their quality of life. This is not surprising since many of the key competencies have similar foci and require the use of the same sorts of skills. For example, Using Language, Symbols \& Texts and Relating To Others both incorporate aspects of self-expression, although each has a slightly different emphasis. It therefore seems understandable 
that the techniques and strategies were found to have supported more than one key competency, especially where competencies shared commonalities.

While it is clear that the interconnected nature of the key competencies helps to explain why a number of techniques and strategies were able to support all five areas, the literature suggests that music works in a similar manner. Pelliterri (2000) states that music therapy is far reaching in nature and has the ability to work toward multiple goals at once. Music is communicative and social at its core, and is underpinned by "unique thinking processes" (O'Connor \& Dunmill, 2005, p. 2), suggesting that the very nature of music directly aligns with the foci of a number of the key competencies. The findings support this, showing that a higher percentage of the musical techniques and strategies supported the key competencies when compared to verbal or physical techniques and strategies. Thus, musical elements used within music therapy sessions may be able to support multiple areas of learning and development more effectively than non-music tools.

\section{Common Techniques and Strategies Within My Music Therapy Practice}

The data identified seven common musical techniques and strategies that supported all five key competencies during music therapy sessions, two of which also included verbal aspects (familiar music; copying students' playing, vocalisations, mood and movements; matching students' playing, vocalisations, mood, movements; lyrical

affirmation; leaving space in the music; holding chords; and singing students' names). Familiar music worked across the competencies to provide a comfortable, recognisable atmosphere to assist in student participation as described by Pellitteri (2000). Copying students' playing, vocalisations, mood and movements, matching students' playing, vocalisations, mood, movements, and lyrical affirmation served to reinforce students' contributions to the sessions in all categories. Leaving space in the music, holding chords and singing students' names worked globally to encourage participation and contribution. Current literature supports the use of a number of 
these techniques and strategies within music therapy practice beyond the special school setting (McFerran \& Shanahan, 2011; Perry, 2003).

A study by McFerran and Shanahan (2011) supports the use of familiar or well known songs, copying, matching and lyrical affirmation when working towards a number of goals with students with high needs in an education setting. While leaving space in the music, holding chords and singing students' names were found to support all five key competencies, they have not been specifically identified within the literature as being commonly used within music therapy practice. However, they were used extensively in the music therapy sessions analysed with a range of students who were working towards a number of different goals. This high level of use, coupled with the knowledge that they supported every key competency, creates a strong case suggesting they have the ability to work universally within music therapy. While there is clear evidence to support this, it is important to note that these findings may simply reflect those techniques and strategies that I frequently employ within my music therapy work rather than those commonly used within music therapy practice.

It is interesting to note that there were very few techniques or strategies that solely and specifically supported the development of a single key competency. The majority of the remaining techniques and strategies were found to support two or more competencies at once - many of which included Using Language, Symbols \& Texts along with at least one other competency. This evidence would suggest that the context provided within music therapy sessions encouraged the development of the key competencies as much as, or perhaps even more than, the specific techniques and strategies employed. Thus it appears that music therapy may be able to support the key competencies regardless of specific session goals or the individual music therapist's style. 


\section{Supporting and Challenging for Success - Finding a Balance}

For those with high or very high complex special needs support is necessary in order to allow opportunities for success and ultimately realise each student's full potential (Ministry of Education, 2007, 2014d). As a music therapy student, I was very aware of this need and aimed to provide adequate support and encouragement during music therapy sessions where required, as explained by Daveson \& Edwards (1998), in order to see students experience success and make progress towards or achieve their goals. The findings reflect this endeavour, describing many of the techniques and strategies that supported session goals, and unknowingly, the key competencies. While physical assistance such as using hand-over-hand may be an obvious form of support, other supportive actions included verbal techniques and strategies such as giving verbal prompts, and most commonly, musical techniques and strategies such as holding chords, leaving space in the music and changing dynamics. The wide range of techniques and strategies used in this way worked in an integrated way to support student success, and others were used to reinforce that success.

The data indicates that a number of musical, physical and verbal techniques and strategies were used to provide support for the students I worked with. These techniques and strategies have the potential to create positive, successful experiences for students and lead to an increased self-esteem and confidence that goes beyond the music therapy sessions (McFerran \& Elefant, 2012). However, the literature also states that it is necessary to challenge students in order to encourage the development of key competencies (Ministry of Education, 2007) and Daveson \& Edwards (1998) suggest that this can also be implemented by the music therapist. When challenging students, I believe it is important that a positive client-therapist relationship has already been established because, as McFerran and Elefant (2012) state, students are more likely to take risks and express themselves in relationships where they feel accepted and respected. 
While it was difficult to find techniques and strategies that worked specifically to challenge students' independent use of the key competencies, a number of those utilised helped to reinforce students' initiations and independence, particularly in the area of Managing Self. This suggests that students were challenged when given opportunities for independence, were able to meet those challenges and their efforts were recognised and responded to constructively (Daveson \& Edwards, 1998). While techniques and strategies that work to support and challenge students' development, participation or contributions need to be employed, students must be motivated to attempt to meet those challenges or else the music therapist's efforts become pointless. The literature and the findings suggest that music therapy can be highly motivating for students with special needs (Daveson \& Edwards, 1998; Pellitteri, 2000; Perry, 2003; Rickson \& McFerran, 2007), "engaging the child and therefore allowing them to achieve their full potential" (Rickson \& McFerran, 2007, p. 42).

While development can be seen 'in the moment' as described by Nordoff \& Robbins (Nordoff-Robbins Music Therapy, 2011), it may be more helpful to assess progress of the key competencies longitudinally, as they are developed over time through a number of interactions and situations (Ministry of Education, 2007). Aspects of Managing Self, such as the 'can-do' attitude, increased resilience and independence are typically developed and observable over time as opposed to 'in the moment'. It is therefore important to provide a range of opportunities for students to successfully practice these skills on an ongoing basis - experiences that music therapy can provide (Daveson \& Edwards, 1998; Pellitteri, 2000). This finding suggests that the music therapist must work hard to maintain mutuality in an ongoing basis, both challenging and supporting participation in order to see success over time. This balance seems to be extremely important if students are to successfully develop the key competencies. 


\section{Engaging in a Musical Conversation}

The focus of this study was to find the techniques and strategies I, the music therapy student, used that supported the development of the key competencies within music therapy sessions. While the findings describe a number of techniques and strategies that worked for this purpose, it is important to view them within the framework of a musical conversation. A conversation is interactive and requires input from two parties, each taking their turn to share an idea before the other responds, and vice versa - skills that Perry (2003) states are predominant in improvisational music therapy. Within this musical framework, students are able to learn and practice initiating conversations (Managing Self), expressing themselves and their ideas (Using Language, Symbols \& Texts and Relating To Others), and responding to others (Participating \& Contributing).

While the findings identify the numerous techniques and strategies that I used to either initiate conversation or respond to a student's expression, it is important to note and emphasise that musical conversation is collaborative, so is not always controlled or directed by the therapist (Perry, 2003). At times during musical conversation I would initiate and the student would respond. For example I would sing the student's name and s/he would vocalise in response. At other times the student would initiate and I would respond, such as when s/he would play the chimes loudly and abruptly, and I would respond by matching the style and dynamic of her/his playing on my guitar. While these musical conversations did involve two parties, I worked hard to meet each student where s/he was, before "gradually demanding more reciprocity in the musical relationship" (McFerran \& Elefant, 2012, p. 54) and musical conversation.

Such conversations require students to assume both leading and responding roles and it is therefore important for the music therapist to find a balance between initiating and responding in order to give students opportunities to practice both roles and develop the corresponding competencies. While it may not be the case for 
all students with special needs or those in mainstream settings, for students with limited communicative abilities, as was the case for many of the students at this school, these musical conversations give students an opportunity to reveal a "communicative capacity ... that is often not evident in other settings" (McFerran \& Shanahan, 2011, p. 104).

It is clear that these musical conversations encouraged the development of the key competencies and helped to support student goals. However, a music-centered approach would suggest that the experience and expression achieved within the musical conversation is the true music therapy goal; other developments are simply a result of that which uniquely occurs within the music (Aigen, 2011). McFerran \& Shoemark (2013) further support this, suggesting that developmental goals should be secondary for students with high or very high complex special needs within music therapy, and achievable goals such as building meaningful relationships should become the focus. With music therapy in schools typically focusing on meeting IEP goals (Daveson \& Edwards, 1998; McFerran \& Shanahan, 2011; Patterson, 2003; Pellitteri, 2000; Stephenson, 2006), it may be difficult to discard these non-musical goals and justify the employment of a music-centered approach. However, this approach appears highly beneficial for those with high or very high complex special needs, shifting the focus back to student wellbeing by placing the musical encounters at the centre of music therapy work.

\section{Future Research}

While this study discovered the techniques and strategies I used within individual music therapy sessions that supported young people with high or very high complex special needs to develop the key competencies, further research would be necessary in order to explore deeper musical links to the competencies. Future studies could include analysis of group sessions and/or microanalysis of video data in order to see how the key competencies are used and supported within the music as opposed to the music therapy session. Video data would provide a more objective and specific 
account of sessions and potentially uncover subtleties within the music that may otherwise be missed.

\section{Limitations of Research}

This study is a response to and result of my music therapy work with students who have high or very high complex special needs. Music therapy sessions were conducted, and data was produced and analysed by myself - taking on the role of both practitioner and researcher. Therefore, the data expresses my interpretations, thoughts and opinions of aspects of music therapy sessions that I deemed important or relevant to my clinical practice. I do not claim that these accounts are necessarily truth; rather they are my own interpretations of what I experienced and witnessed. The data is, however, informed by my knowledge of the students through my own past experiences and encounters with them, and their encounters with other professionals.

This study employed a method of secondary analysis, using pre-produced data to answer a new question. It was therefore imperative that all data was produced solely for the purpose of my clinical practice if this method was to be utilised correctly. As my clinical practice and research were undertaken concurrently, there was a risk that the data would be influenced by my thoughts about potential results. Being aware of this, I worked hard to separate my thoughts about the research while at the school so as to produce unbiased data. Further precautions were taken by not beginning the analysis process until all data had been collected - following the accepted method of secondary analysis.

This study expresses the links between the key competencies outlined in the New Zealand Curriculum (Ministry of Education, 2007) and my music therapy practice with young people who have high or very high complex special needs.

Generalisations should not be made regarding this research, as it is specific to one school, however the findings could be used to inform further research in this area. 


\section{CONCLUSION}

In this research, I attempted to examine my own music therapy work in order to discover any potential of supporting the development of the key competencies in music therapy with young people who have high or very high complex special needs. This exploratory study revealed that I used many musical, verbal and physical techniques and strategies that supported the development of each of the key competencies. The holistic nature of music therapy as a tool for supporting development and wellbeing in this population group was evident in this study. Many of the techniques and strategies employed within music therapy sessions provided support for all five key competencies, even when the focus was a single competency. While these findings suggest that music therapy work in this area could be promising, I propose that it may be more valuable for music therapists to adopt a music-centred approach when working with this population. The music itself would then become the focus rather than developmental goals, placing a greater emphasis and importance on the musical experiences and student wellbeing. In doing this, students still have the potential to make progress towards other goals and/or the key competencies within the musical environment while emphasising the importance and benefits of the music itself. 


\section{REFERENCES}

Adamek, M. S., \& Darrow, A. (2010). Music in special education. Silver Spring, MD: American Music Therapy Association.

Aigen, K. (2011). Music-Centered Music Therapy (Kindle Locations 1238-1254). Barcelona Publishers. Kindle Edition.

American Music Therapy Association. (2006). Music Therapy and Special Education. American Music Therapy Association. Retrieved from http://www.musictherapy.org/assets/1/7/MT_Special_Ed_2006.pdf American Music Therapy Association. (n.d.). Special Education: Music Therapy Research and Evidence-Based Practice Support. American Music Therapy Association. Retrieved from http://www.musictherapy.org/assets/1/7/bib_Special_Education.pdf

Boxill, E. H. (1985). Music Terapy for the developmentally disabled. Rockville: Aspen.

Braun, V., \& Clarke, V. (2006). Using thematic analysis in psychology. Qualitative Research in Psychology, 3(2), 77-101.

Brewerton, M. (2004, February). Reframing the essential skills: Implications of the OECD Defining and Selecting Key Competencies Project - A background paper. Retrieved from http://nzcurriculum.tki.org.nz/Archives/Curriculumproject-archives/References

Bruscia, K. E. (2005). Standards of Integrity for Qualitative Music Therapy Research. Voices: A World Forum for Music Therapy, 5(3). Retrieved from https://voices.no/index.php/voices/article/view/238/182 
Cheng, E., Ockelford, A., \& Welch, G. (2009). Researching and Developing Music Provision in Special Schools in England for Children and Young People with Complex Needs. Australian Journal of Music Education, (2), 27-48.

Clerkin, C. (2013). Beyond imitation, without limitations : a student music therapist supports the participation and development of young people with profound and multiple learning difficulties in a school setting : an exegesis submitted to Massey University and Victoria University of Wellington in partial fulfillment for the degree of Master of Music Therapy New Zealand School of Music. New Zealand School of Music, Wellington.

Daveson, B., \& Edwards, J. (1998). A Role for Music Therapy in Special Education. International Journal of Disability, Development and Education, 45(4), 44957.

DeBedout, J. K., \& Worden, M. C. (2006). Motivators for children with severe intellectual disabilities in the self-contained classroom: A movement analysis. Journal of Music Therapy, 43(2), 123-135.

De Mers, C. L., Tincani, M., Van Norman, R. K., \& Higgins, K. (2009). Effects of music therapy on young children's challenging behaviors: A case study. Music Therapy Perspectives, 27(2), 88-96.

Edwards, J. (1999). Considering the Paradigmatic Frame: Social science research approaches relevant to research in music therapy. The Arts in Psychotherapy, $26(2), 73-80$.

Edwards, J. (2005). Possibilities and problems for evidence-based practice in music therapy. The Arts in Psychotherapy, 32(4), 293-301. 
Eisner, Elliot W. (2002). The Arts and the Creation of Mind. New Haven: Yale University Press.

Foran, L. M. (2009). Listening to Music: Helping Children Regulate Their Emotions and Improve Learning in the Classroom. Educational Horizons, 88(1), 51-58.

Gooding, L. F. (2011). The effect of a music therapy social skills training program on improving social competence in children and adolescents with social skills deficits. Journal of Music Therapy, 48(4), 440-462.

Halligan, L. J. (2012). How does my music therapy practice, in a transition school focused on supporting adolescents with mental health needs, relate to the key competencies of the New Zealand curriculum? : an exegesis presented in partial fulfilment of the requirements for the degree of Master of Music Therapy at Massey University, Wellington, New Zealand. New Zealand School of Music, Wellington.

Heaton, J. (2008). Secondary Analysis of Qualitative Data: An Overview. Historical Social Research, 33(3), 33-45.

Hipkins, R. (2006). The Nature of the Key Competencies: A Background Paper. New Zealand Council For Educational Research. Retrieved from http://nzcurriculum.tki.org.nz/Archives/Curriculum-projectarchives/References

Irwin, S. (2013). Qualitative Secondary Data Analysis: Ethics, epistemology and context. SAGE Publications, 13(4), 295-306.

Johnson, F. L. (2002). Models of Service Delivery and Their Relation to the IEP. In B. L. Wilson (Ed.), Models of Music Therapy Interventions in School Settings (pp. 83-108). Silver Spring, MD: The American Music Theray Association, Inc. 
Kaplan, R. S., \& Steele, A. L. (2005). An Analysis of Music Therapy Program Goals and Outcomes for Clients with Diagnoses on the Autism Spectrum. Journal of Music Therapy, 42(1), 2-19.

KCP Curriculum Group. (2012). Key Competencies Pathway. Auckland: KCP Curriculum Group.

Kennedy, R., \& Scott, A. (2005). A Pilot Study: The Effects of Music Therapy Interventions on Middle School Students' ESL Skills. Journal of Music Therapy, 42(4), 244-261.

Malterud, K. (2001). Qualitative research: standards, challenges, and guidelines. Lancet, 358(9280), 483-488.

McFerran, K., \& Elefant, C. (2012). A fresh look at music therapy in special education. In Oxford handbook of music education (Vol. 2, pp. 51-64). Oxford: Oxford University Press.

McFerran, K., \& Shanahan, E. (2011). Music Therapy Practice in Special Education and Children's Hospice: A Systematic Comparison of Two Music Therapists' Strategies with Three Preadolescent Boys. Music Therapy Perspectives, 29(2), 103-111.

McFerran, K., \& Shoemark, H. (2013). How musical engagement promotes well-being in education contexts: The case of a young man with profound and multiple disabilities. International Journal of Qualitative Studies on Health and WellBeing, 8(1).

Minister for Disability Issues. (2001). The New Zealand Disability Strategy: Making a World of Difference Whakanui Oranga. Wellington: Ministry of Health. 
Retrieved from http://www.odi.govt.nz/documents/publications/nzdisability-strategy.pdf

Ministry of Education. (2005, March). Key Competencies: The New Zealand Curriculum/Marautanga Project. Ministry of Education. Retrieved from http://nzcurriculum.tki.org.nz/Archives/Curriculum-projectarchives/References\#Key_competencies

Ministry of Education. (2007). The New Zealand Curriculum. Wellington: Learning Media.

Ministry of Education. (2011). Collaboration for Success: Individual Education Plans. Wellington: Learning Media.

Ministry of Education. (2014a). Education Act 1989. Paliamentary Counsel Office. Retrieved from http://www.legislation.govt.nz/act/public/1989/0080/latest/whole.htmI\#DL M177470

Ministry of Education. (2014b). Education and disability contexts. Ministry of Education. Retrieved from http://www.minedu.govt.nz/NZEducation/EducationPolicies/SpecialEducatio n/AboutUs/ContextOfOurWork/EducationAndDisabilityContexts.aspx Ministry of Education. (2014c). Ongoing Resourcing Scheme (ORS). Ministry of Education. Retrieved from http://www.minedu.govt.nz/NZEducation/EducationPolicies/SpecialEducatio n/ServicesAndSupport/OngoingResourcingScheme.aspx

Ministry of Education. (2014d). Special Education Policy Guidelines: Introduction. Ministry of Education. Retrieved from 
http://www.minedu.govt.nz/NZEducation/EducationPolicies/SpecialEducatio n/AboutUs/ContextOfOurWork/SpecialEducationPolicyGuidelines/Introducti on.aspx

Ministry of Education. (2014e). Success for All: Every school, every child. Ministry of Education. Retrieved from http://www.minedu.govt.nz/ /media/MinEdu/Files/EducationSectors/Specia IEducation/SuccessForAllEnglish.pdf

Nelson, C. L. (2010). Meeting the Needs of Urban Students: Creative Arts Therapy in Jersey City Public Schools. Art Therapy: Journal of the American Art Therapy Association, 27(2), 62-68.

Nordoff-Robbins Music Therapy. (2011). Music Therapy. Nordoff-Robbins Music Therapy. Retrieved from http://www.nordoff-robbins.org.uk/content/whatwe-do/music-therapy

O'Connor, D. P., \& Dunmill, M. (2005, August). Key Competencies and The Arts in the New Zealand Curriculum. Ministry of Education. Retrieved from http://nzcurriculum.tki.org.nz/Archives/Curriculum-projectarchives/References

Patterson, A. (2003). Music Teachers and Music Therapists: Helping Children Together. Music Educators Journal, (4), 35.

Pavlicevic, M., Ansdell, G., Procter, S., \& Hickey, S. (2009). Presenting the evidence: the up to date guide for music therapists responding to demands of clinical effectiveness and evidence-based practice. London: Nordoff-Robbins Music Therapy Centre. Retrieved from http://www.nordoffrobbins.org.uk/sites/default/files/Presenting\%20The\%20Evidence_1.pdf 
Pellitteri, J. (2000). Music therapy in the special education setting. Journal of Educational \& Psychological Consultation, 11(3-4), 379-391.

Perry, M. R. (2003). Relating improvisational music therapy with severely and multiply disabled children to communication development. Journal of Music Therapy, 40(3), 227-246.

Pienaar, D. (2012). Music Therapy for Children with Down Syndrome: Perceptions of Caregivers in a Special School Setting. Kairaranga, 13(1), 36-43.

Potter, W. J. (1996). An analysis of thinking and research about qualitative methods. Hillsdale, NJ: Lawrence Erlbaum Associates.

Rickson, D. J. (2006). Instructional and improvisational models of music therapy with adolescents who have Attention Deficit Hyperactivity Disorder (ADHD): A comparison of the effects on motor impulsivity. Journal of Music Therapy, 43(1), 39-62.

Rickson, D. J., \& McFerran, K. (2007). Music Therapy in Special Education: Where Are We Now? Kairaranga, 8(1), 40-47.

Rickson, D. J., \& Watkins, W. G. (2003). Music Therapy to Promote Prosocial Behaviors in Aggressive Adolescent Boys - A Pilot Study. Journal of Music Therapy, 40(4), 283-301.

Rickson, D., \& Skewes McFerran, K. (2014). Creating music cultures in the schools: a perspective from community music therapy. University Park, IL : Barcelona Publishers.

Robb, S. L. (2003). Music interventions and group participation skills of preschoolers with visual impairments: Raising questions about music, arousal, and attention. Journal of Music Therapy, 40(4), 266-282. 
Rutherford, J. (2004, December). Key Competencies in the New Zealand Curriculum:

A snapshot of consultation. Retrieved from

http://nzcurriculum.tki.org.nz/Archives/Curriculum-project-

archives/References

Stephenson, J. (2006). Music Therapy and the Education of Students with Severe

Disabilities. Education and Training in Developmental Disabilities, 41(3), 290299.

Tomlinson, J., Derrington, P., \& Oldfield, A. (Eds.). (2012). Music therapy in schools :

working with children of all ages in mainstream and special education.

Philadelphia: Jessica Kingsley Publishers.

Turnbull, H. R., \& Turnbull, A. P. (1998). Free appropiate public education (5th ed.). Denver: Love.

Twyford, K. (2009). Finding a niche: Establishing a role for music therapy within the Ministry of Education, Special Education NZ. New Zealand Journal of Music Therapy, (7), 6-31.

Twyford, K. (2013). Introducing time defined Specialist Music Therapy Services within the Ministry of Education Special Education, NZ: Outcomes from a pilot project study. New Zealand Journal of Music Therapy, (11), 104-132.

Vaismoradi, M., Turunen, H., \& Bondas, T. (2013). Content analysis and thematic analysis: Implications for conducting a qualitative descriptive study. Nursing \& Health Sciences, 15(3), 398-405.

Wheeler, B. L. (2005). Music Therapy Research. Gilsum, NH: Barcelona Publishers.

Yardley, L., \& Marks, D. (2004). Research Methods for Clinical and Health Psychology. London: SAGE. 
Youngshin Kim. (2004). The Early Beginnings of Nordoff-Robbins Music Therapy. Journal of Music Therapy, 41(4), 321-339. 


\section{APPENDIX 1: Example of Initial Coding}

Ben - Session 10

Ben was quite tired after his swimming session today and was finding it difficult to hold his head up - MT had to keep reminding him (verbal prompt) about it or physically help him (hand-over-hand) to put his head back in his head rest Ben listened to MT sing and play the hello song (familiar music)

MT left a space (left a space in the music) for Ben to respond and say hello using his voice and he did vocalise 'ah' and smiled after MT prompted him (verbal prompt) 'are you going to say hello, Ben?'

MT asked Ben if he would like to play the chimes (choice) and he immediately smiled and vocalised - MT replied 'was that a yes? Yes!' (verbal question) and Ben vocalised again 'ah'

Ben immediately began to lift his hands toward the chimes when they were in front of him

MT played chords for song on the guitar to start to see what Ben was going to do and he lifted his hands a few times to play the chimes

MT sung, "stretch out your hands, Ben (Iyrical instruction). I want to hear you play!" and Ben smiled and laughed and lifted up his hands to play the chimes

MT continued this for a while and then began to improvise (improvisation) and sing about what Ben was doing (lyrical affirmation) - looking at the chimes, lifting up his hands - as well as encouraging him - "I love to hear you play, Ben", "I can hear Ben on the chimes", "go Ben!"

At points where Ben had stopped to play, MT held a chord (holds chords), starting quietly and getting louder (changes dynamics), in an attempt to create a suspense and encourage Ben to play

This usually worked, with Ben either laughing or vocalising and/or lifting up his hands to play the chimes

At the end of this, MT asked Ben if he would like more chimes (choice) or to move on to something else

Ben quickly vocalised 'ah' and smiled after MT said 'more' (verbal prompt)

MT encouraged Ben to say 'more' and he was able to put his lips to together a few times and also vocalise 'ore' (separately)

MT started song again and it proceeded in the same manor

MT paused at the end of the song (pause) to see what Ben' reaction would be and he put his lips together, creating his ' $\mathrm{mmmm}$ ' lips

MT took this to mean that he wanted 'more' and so played the song one more time After this, MT brought over the drum to play "the ants go marching" (familiar music) Ben lifted his hands onto the drum (at first clentched)

MT started singing the song and playing the drum, and helping Ben to play at times by using hand-over-hand (hand-over-hand) to lift up his hand and play Ben laughed and vocalised at this, especially when MT sped up the song (changes tempo) and made him play faster

As the song continued, Ben's hand seemed to become flatter and less tense on the drum and almost ended in a flat position 


\section{APPENDIX 2: Example of Sorting Initial Codes}

\begin{tabular}{|c|c|c|}
\hline Code & Data Text & $\begin{array}{c}\text { Student } \\
\text { Identifier/Date } \\
\end{array}$ \\
\hline $\begin{array}{l}\text { MT asks verbal } \\
\text { question }\end{array}$ & $\begin{array}{l}\text { MT said hi and asked if S was ready for } \\
\text { music }\end{array}$ & S, 17 June \\
\hline MT attempts to calm & $\begin{array}{l}\text { It was getting close to the end of the } \\
\text { session of MT began to play gentle } \\
\text { keyboard music to calm her }\end{array}$ & S, 10 June \\
\hline MT attempts to calm & $\begin{array}{l}\text { MT began to play slow, gentle music to } \\
\text { try and calm } \mathrm{S} \text { before the end of the } \\
\text { session }\end{array}$ & S, 6 June \\
\hline MT attempts to calm & $\begin{array}{l}\text { S got very excited so MT began to play } \\
\text { softer music to try and calm } S \text { down }\end{array}$ & S, 3 June \\
\hline MT challenges & $\begin{array}{l}\text { MT kept the drum up high for a few more } \\
\text { minutes after } N \text { had dropped his head }\end{array}$ & N, 13 June \\
\hline MT changed playing & $\begin{array}{l}\text { D responded the best by lifting his hands } \\
\text { after MT played staccato chords }\end{array}$ & D, 11 June \\
\hline MT changes dynamics & $\begin{array}{l}\text { At points where } D \text { stopped playing, MT } \\
\text { held a chord, starting to play quietly and } \\
\text { then getting louder in an attempt to } \\
\text { encourage } D \text { to play }\end{array}$ & D, 4 June \\
\hline MT changes dynamics & $\begin{array}{l}\text { MT began to play chords to hello song, } \\
\text { holding chords, starting quietly and } \\
\text { building to loud }\end{array}$ & S, 3 June \\
\hline MT changes dynamics & $\begin{array}{l}\text { MT encouraged MA to play by playing } \\
\text { slowly and then building music up, MA } \\
\text { moved body and sometimes played keys }\end{array}$ & MA, 27 May \\
\hline $\begin{array}{l}\text { MT changes position } \\
\text { of instrument }\end{array}$ & $\begin{array}{l}\text { MT changed the ukulele to be standing } \\
\text { up so that she could play it more } \\
\text { effectively }\end{array}$ & $\mathrm{T}, 10$ June \\
\hline MT changes tempo & $\begin{array}{l}\text { D laughed especially when MT sped up } \\
\text { the song }\end{array}$ & D, 4 June \\
\hline MT changes tempo & $\begin{array}{l}\text { D laughed when MT began to play "the } \\
\text { ants go marching" and laughed even } \\
\text { more when MT sped up at the end of } \\
\text { each verse }\end{array}$ & D, 11 June \\
\hline MT changes tempo & $\begin{array}{l}\text { MT encouraged MA to play by playing } \\
\text { slowly and then building music up, MA } \\
\text { moved body and sometimes played keys }\end{array}$ & MA, 27 May \\
\hline MT changes tempo & $\begin{array}{l}\text { MT repeated 'cha cha cha' and changed } \\
\text { the tempo, going faster and slower }\end{array}$ & $\mathrm{T}, 10$ June \\
\hline MT changes tempo & $\begin{array}{l}\text { MT slowed and sped up the song, D } \\
\text { laughed and enjoyed it especially as MT } \\
\text { got faster }\end{array}$ & D, 7 May \\
\hline
\end{tabular}




\section{APPENDIX 3: Example of Emerging Themes}

\section{MANAGING SELF}

Physical

- Allows participant to act independently

- Copies movements

- Follows participant

- Matches movement

- Models

- Positions/repositions instruments

- Uses action song

- Uses hand-over-hand

\section{Musical}

- Attempts to calm

- Changes dynamics

- Changes style of playing

- Changes tempo

- Copies playing

- Copies vocalisations

- Follows participant

- Holds chords

- Introduces a new sound

- Leaves space in the music

- Matches mood

- Matches movement

- Matches playing

- Offers lyrical choice

- Sings name

- Uses action song

- Uses familiar music

- Uses lyrical affirmation

- Uses lyrical instruction

- Uses repetition

Verbal

- Sings name

- Uses lyrical affirmation

- Uses lyrical instruction

- Uses song in first language

- Uses verbal affirmation

- Uses verbal instruction

- Uses verbal prompt 


\section{APPENDIX 4: Cover Letter for Facility}

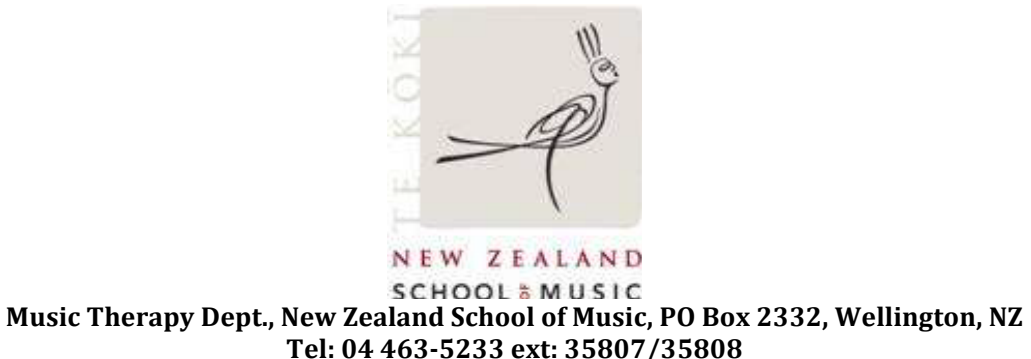

Tel: 04 463-5233 ext: $35807 / 35808$

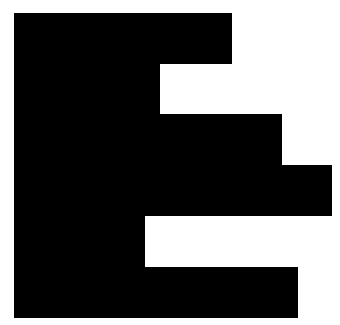

16 May 2014

\section{Dear}

\section{RE: Music Therapy Research Study at}

The purpose of this letter is to request your permission for me to review music therapy clinical documentation - that I have been keeping as part of my practice for research purposes. As you may know, my work at $\quad$ is a part-fulfilment of the course requirements for the Master of Music Therapy programme taught through the New Zealand School of Music. As well as having a practical component to the course, I must also carry out a research task related to my clinical work. My research exegesis is due at the end of the year.

I have the approval of the Massey University Human Ethics Committee (MUHEC) to undertake a secondary analysis of data. This involves looking back over existing data to answer a new question. Throughout my placement it has been important for me to fulfil my clinical practice as if there was no research to be carried out in the future, thus minimising any conflict of interest for me and optimising the quality of music therapy that student's receive. For school records I have attached the MUHEC approval document to this letter (HEC: Southern A Application -11/41).

I submitted a research proposal to the New Zealand School of Music Postgraduate Committee, and received their approval to research the specific question that I outlined. The approved question for my research paper is: 'How does a student music therapist support students with high and very high complex special needs to develop the Key Competencies outlined in the New Zealand Curriculum?' For your information I have attached my complete research proposal. Throughout my time working in the school, I have been recording my observations and thoughts from music therapy sessions in notebooks and on computers. I would like to use this data 
to answer my research question. The primary focus would be on my own work as a music therapy student rather than on students. However, in order to contextualise my work there may be a need to describe student responses, or interactions with staff, or the content of my supervision sessions with W. Where this occurs I would also seek informed consent directly from those affected.

I am in the process of composing the necessary information sheets for parents and staff, and will share these with you before I send them out. Included in these sheets will be information about myself (my background and current role), the topic of my research and what methods I will use, as well as how data will be used and stored. It will also aim to inform people about their rights. Following the satisfactory completion of information sheets, I will be writing consent forms so that those people who may be implicated in my research can expressly state whether or not they give permission for me to use data in which they may be identifiable.

My research paper will be complete by mid-December 2014, and the school will be able to access a summary of my work following its finalisation. I welcome any questions that you might have regarding anything mentioned above, and feel free to email me for more information. You are also welcome to contact my supervisor, if you have any questions or concerns about this project. Her details are below.

Best wishes,

Sarah Hall

Supervisor:

Dr Daphne Rickson, Senior Lecturer (Music Therapy)

Daphne.Rickson@nzsm.ac.nz

Phone: $044635233 \times 35808$ 


\section{APPENDIX 5: Consent Form for Facility}

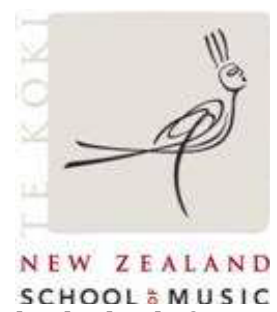

Music Therapy Dept., New Zealand School of Music, PO Box 2332, Wellington, NZ

\section{Consent Form for Music Therapy Research at}

Title of Study: Supporting Young People with High or Very High Complex Special Needs to Develop the Key Competencies Outlined in the New Zealand Curriculum

Please read the following statements. If you agree with them, please sign your name at the end of this form. A copy will be provided for you to keep.

1. I understand that Sarah Hall has been working at as a final year student of the NZSM Master of Music Therapy Programme, and that she is required to review and evaluate information documenting her music therapy experiences in the school for the purposes of completing a research project.

2. I have read and understand the information sheet about the above study. I have had all questions answered to my satisfaction, and understand that I may continue to seek clarification from the researcher or her supervisor on issues pertaining to this study, at any time.

3. I understand that any personal information regarding people involved with the study will only be shared with the researcher's supervisor, the university committee elected to examine the research, and with music therapy students and professionals who might attend a confidential professional presentation at the New Zealand School of Music.

4. I understand that a case study will be presented and discussed at the researcher's final end-of-year examination in December 2014.

5. I understand that no real names will be used in the written documents, and the location of the school will be disguised to protect the identity of those involved in this study.

6. I am aware that will be able to access a summary of the work following its finalisation.

7. I am satisfied that all information about this research has been presented and communicated clearly.

8. I give consent for music therapy data relating to students at used in this study. 
Signed:

Print Name:

Date: 


\section{APPENDIX 6: Cover Letter for Families}

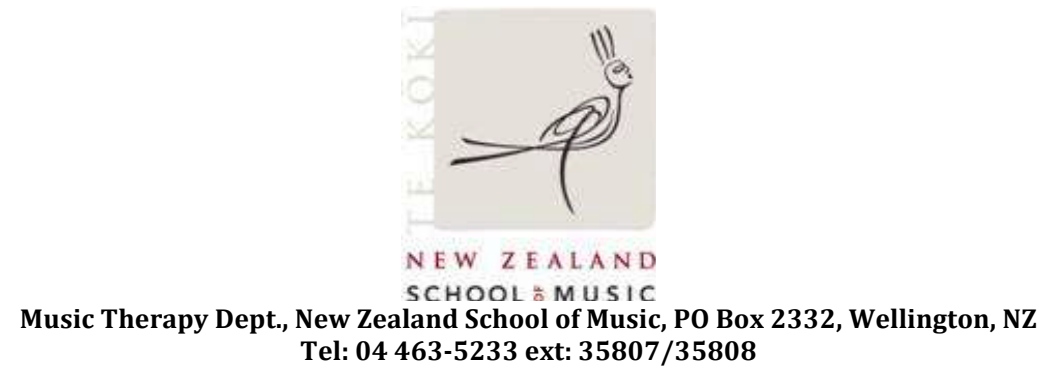

Tel: 04 463-5233 ext: $35807 / 35808$

16 May 2014

Dear

I am a student music therapist, working with since February of this year. I have been involved with in music therapy since the beginning of my placement at and had the pleasure of meeting you at IEP meeting. I have highly valued the time that I have been able to spend with over the past few months, getting to know him as a student, and more generally as a person. I am writing today to inform you about my upcoming research and to ask if you would find it acceptable that I include a vignette (short story-like description of a music therapy session) of my work with $\quad$ in music therapy in my research.

I have attached an information sheet to this letter so that you can acquaint yourselves with my work and study, and feel comfortable about what I am asking of you. Following a reading of the information sheet, if you are satisfied, the next step would be to consider signing the consent form (also attached). This would give permission for me to include a vignette of my work with _ in my research project.

I would be grateful if you could respond or return the information and consent forms by $23^{\text {rd }}$ September, however, there is some leeway if you wish to consider my request in more detail.

I look forward to hearing from you,

Sarah Hall

Supervisor:

Dr Daphne Rickson, Senior Lecturer (Music Therapy)

Daphne.Rickson@nzsm.ac.nz

Phone: 044635233 x35808 


\section{APPENDIX 7: Information Sheet for Families}

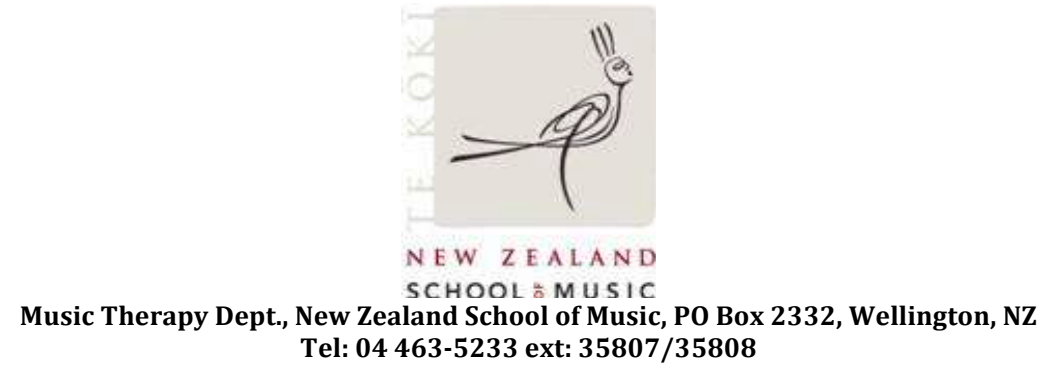

$\frac{\text { Information Sheet for Parents/Guardians - Vignette in a Music Therapy Research }}{\text { Project }}$

Title of Project: Supporting You People with High or Very High Complex Special Needs to Develop the Key Competencies outlines in the New Zealand Curriculum

Dear

My name is Sarah Hall, and I am a Master of Music Therapy student with the New Zealand School of Music. As part of my second year assessment, I have been working at on a year-long clinical work placement to practice my skills as a music therapist. As well as enahancing the education and wellbeing of the students at my work at the school is also aimed at helping me progress as a clinician and researcher. I am writing to you because I would like to include a vignette of my work with within my research project. I will now tell you about the research.

\section{The Research}

Before starting my work at I began to familiarise myself with the New Zealand Curriculum (NZC) and education within special education settings in both New Zealand and around the world. I became interested in the five Key Competencies outlined in the NZC and their importance for students with special needs to access the world around them and meet their full potential. I knew that music therapy was able to support educational/IEP goals and promote wellbeing, but wondered if I was able to support the development of the Key Competencies within music therapy session while focusing on other educational/IEP goals. As I read and began to understand the Key Competencies I saw many links between them and goals that music therapists often work towards with students with special needs.

I submitted a research proposal to the New Zealand School of Music Postgraduate Committee, and received their approval to research the specific question that I outlined. The approved question for my research paper is: 'How does a student music therapist support students with high and very high complex special needs to develop the Key Competencies outlined in the New Zealand Curriculum?' The research will look specifically at the techniques and methods that I have used in music therapy sessions to help and support the development of the Key Competencies while working on other educational/IEP goals. 
The final research document, a written exegesis, will be available in the libraries at both Massey and Victoria universities.

\section{Why Consent is Being Requested}

Currently I have permission from Massey University, the New Zealand School of Music, and to carry out my work as a music therapist and researcher. I have been recording my observations and thoughts as part of my work as a music therapist with the view to improve my music therapy services for the students. I would like to include a short story-like description of a music therapy session in which has participated to help me illustrate central points of my thesis. This vignette, as it is officially known, will describe my work with _ in some detail, and whilst I will de-identify names and places as much as possible for the sake of facility and personal anonymity, there will still be a chance that readers of the research may be able to figure out the location of work and people involved. I will need your informed consent to allow me to include a vignette from my work with in my research project. Should you be happy to provide consent, this could enable me to better answer my research question and potentially help future music therapists enhance their clinical skills for the benefit of young people with special needs.

\section{Your Rights}

You do not have to give permission for me to present a case study about my work with You have the right to ask questions at any time. You have the right to withdraw your permission if you have concerns about the way the research is being carried out. You have the right to ask to be given access to a summary of the case study once the examination is complete.

\section{Contact Details}

If at any point you have any concerns or further questions about this matter, please do not hesitate to contact either myself supervisor Daphne Rickson for further information.

I look forward to hearing from you,

Sarah Hall 


\section{APPENDIX 8: Consent Form for Families:}

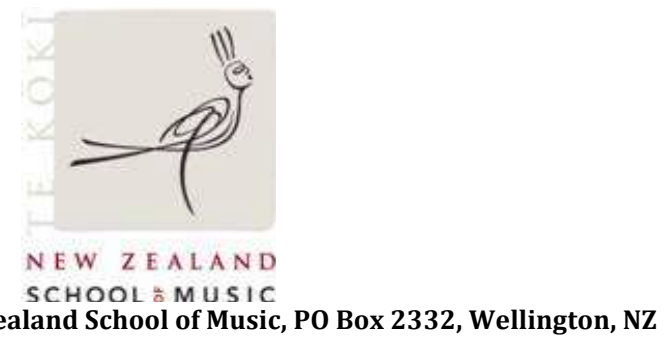

\section{Parent/Guardian Consent Form for Music Therapy Research at}

Title of Study: Supporting Young People with High or Very High Complex Special Needs to Develop the Key Competencies Outlined in the New Zealand Curriculum

Please read the following statements. If you agree with them, please sign your name at the end of this form. A copy will be provided for you to keep.

9. I understand that Sarah Hall has been working at as a final year student of the NZSM Master of Music Therapy Programme, and that she is required to review and evaluate information documenting her music therapy experiences in the school for the purposes of completing a research project.

10. I have read and understand the information sheet about the above study. I have had all questions answered to my satisfaction, and understand that I may continue to seek clarification from the researcher or her supervisor on issues pertaining to this study, at any time.

11. I understand that any personal information regarding will only be shared with the researcher's supervisor, the university committee elected to examine the research, and with music therapy students and professionals who might attend a confidential professional presentation at the New Zealand School of Music.

12. I understand that a particular example of music therapy work with $\square$ may be included as a vignette in the completed written exegesis to illustrate important themes in the research.

13. I understand that no real names will be used in the written documents, and the location of the school will be disguised to protect the identity of those involved in this study.

14. I am aware that I will be able to access a summary of the work following its finalisation.

15. I am satisfied that all information about this research has been presented and communicated clearly.

16. I give consent for music therapy data relating to Dennis to be used in this study.

Signed: Print Name:

Date: 


\section{APPENDIX 9: Overview of the Key Competencies Pathway}

(KCP Curriculum Group, 2012, I Can Statements section)

\begin{tabular}{|c|c|c|c|c|c|c|c|}
\hline 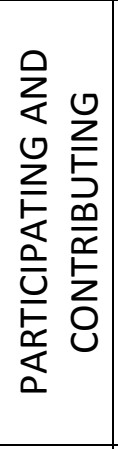 & 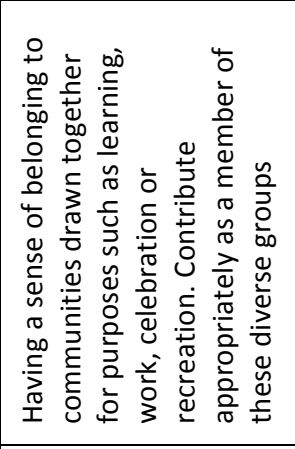 & 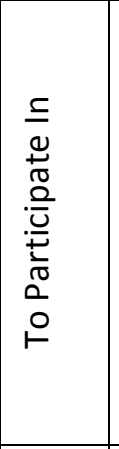 & 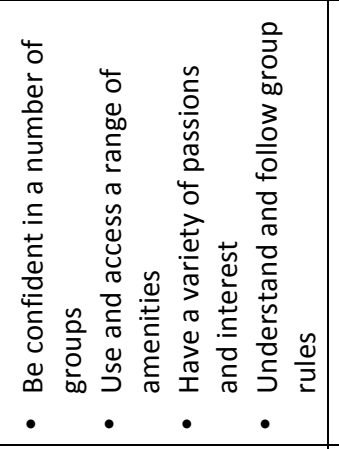 & 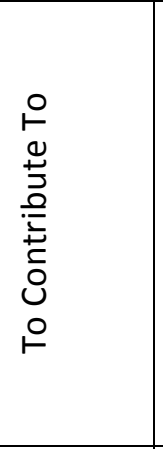 & 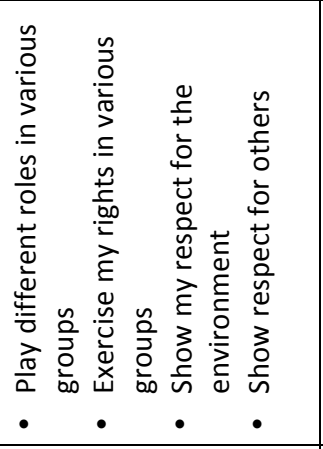 & & \\
\hline 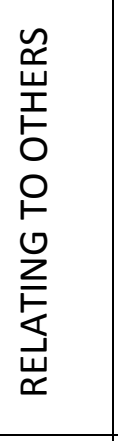 & 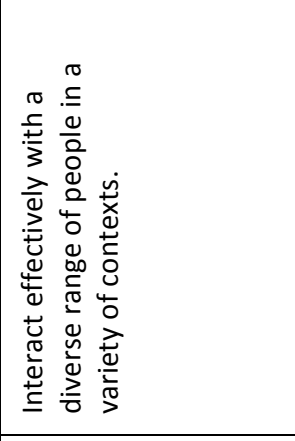 & 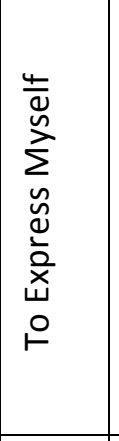 & 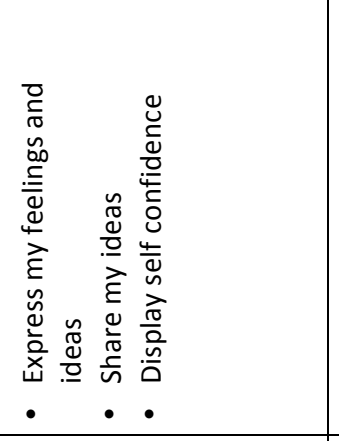 & 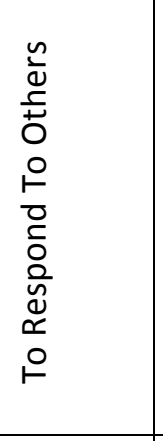 & 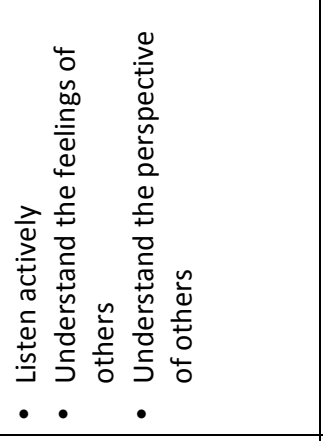 & 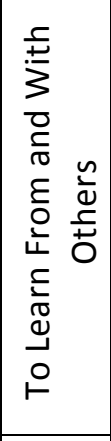 & 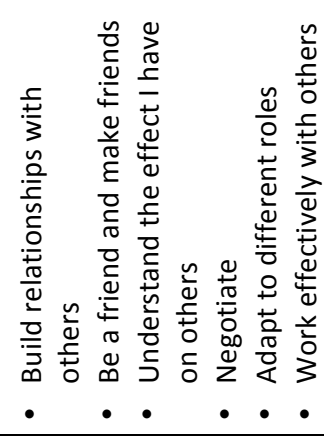 \\
\hline 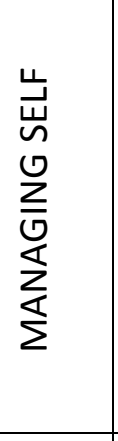 & 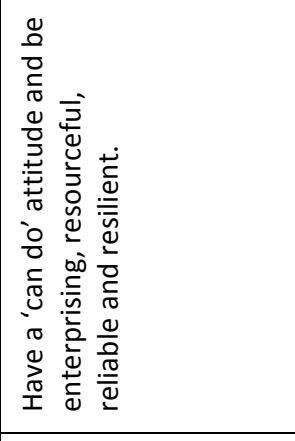 & 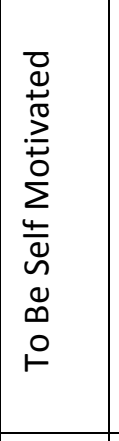 & 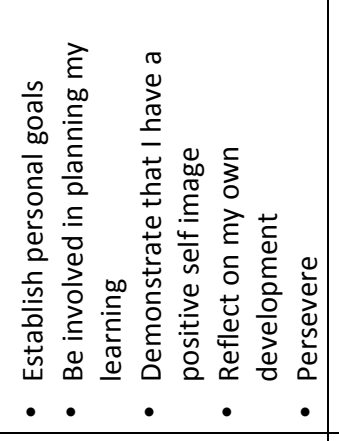 & 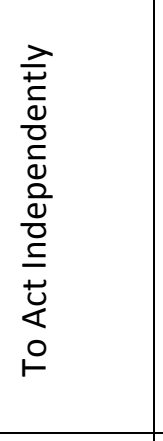 & 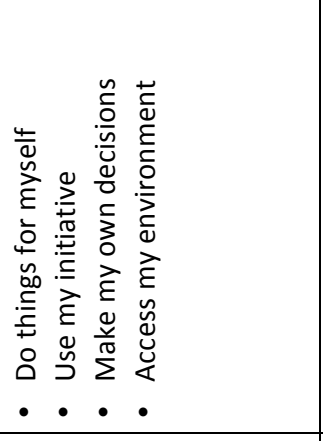 & 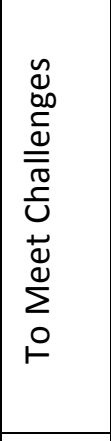 & 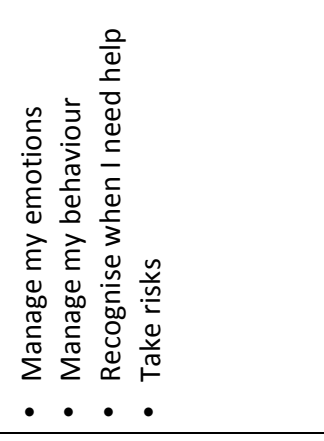 \\
\hline 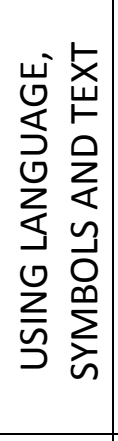 & 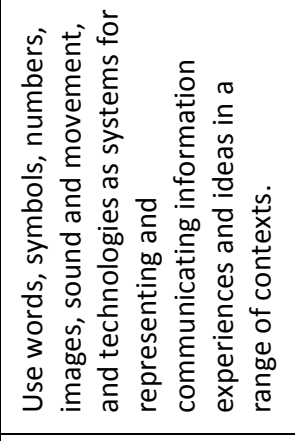 & 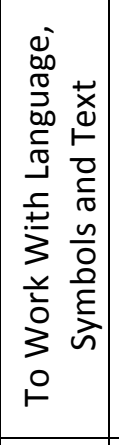 & 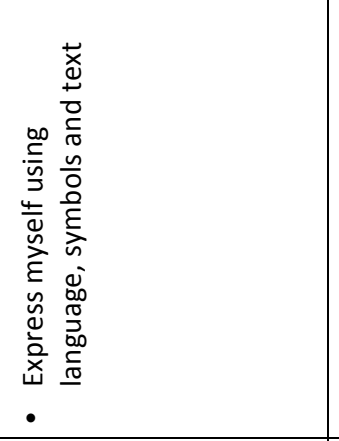 & 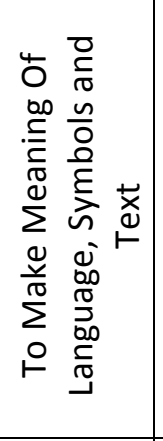 & 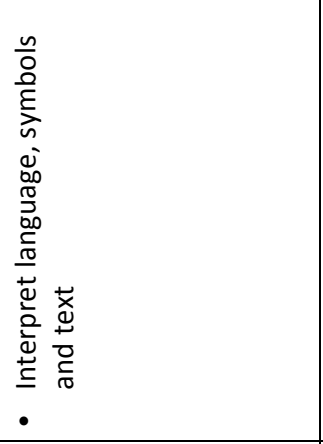 & & \\
\hline $\begin{array}{l}\text { D } \\
\text { 兰 } \\
\text { Ż } \\
\text { I }\end{array}$ & 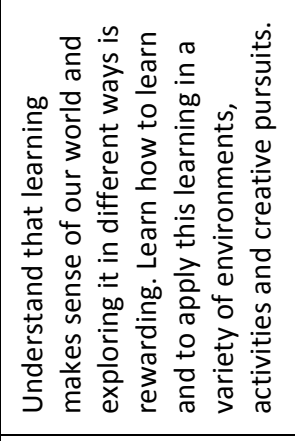 & 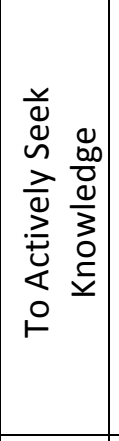 & 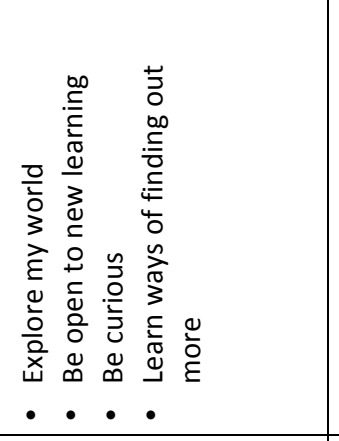 & $\begin{array}{l}0 \\
00 \\
0 \\
\frac{0}{3} \\
3 \\
0 \\
\frac{1}{2} \\
\frac{1}{2} \\
0 \\
\frac{0}{2} \\
0 \\
0\end{array}$ & 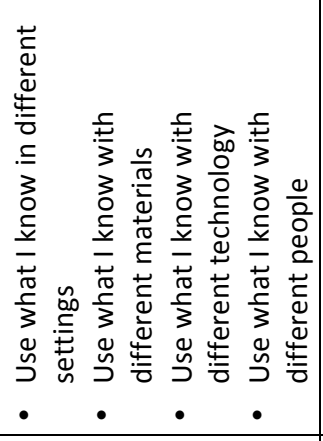 & 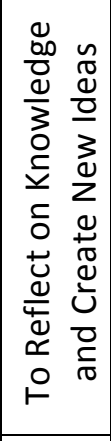 & 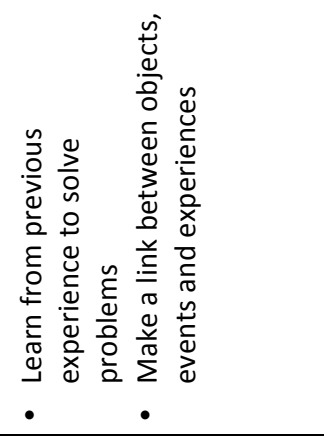 \\
\hline & 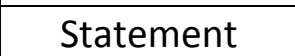 & & $\mathrm{I} \mathrm{ca}$ & & I can & & \\
\hline
\end{tabular}

